\title{
Changes in the CFC Inventories and Formation Rates of Upper Labrador Sea Water, 1997-2001
}

\author{
Dagmar Kieke and Monika Rhein \\ Institut für Umweltphysik, Universität Bremen, Bremen, Germany \\ LOTHAR STRAMMA \\ Leibniz-Institut für Meereswissenschaften IFM-GEOMAR, Kiel, Germany \\ William M. Smethie and Deborah A. LeBel \\ Lamont-Doherty Earth Observatory, Columbia University, Palisades, New York \\ WALTER ZENK \\ Leibniz-Institut für Meereswissenschaften IFM-GEOMAR, Kiel, Germany
}

(Manuscript received 14 April 2003, in final form 6 May 2005)

\begin{abstract}
Chlorofluorocarbon (component CFC-11) and hydrographic data from 1997, 1999, and 2001 are presented to track the large-scale spreading of the Upper Labrador Sea Water (ULSW) in the subpolar gyre of the North Atlantic Ocean. ULSW is CFC rich and comparatively low in salinity. It is located on top of the denser "classical" Labrador Sea Water (LSW), defined in the density range $\sigma_{\Theta}=27.68-27.74 \mathrm{~kg} \mathrm{~m}^{-3}$. It follows spreading pathways similar to LSW and has entered the eastern North Atlantic. Despite data gaps, the CFC- 11 inventories of ULSW in the subpolar North Atlantic $\left(40^{\circ}-65^{\circ} \mathrm{N}\right)$ could be estimated within $11 \%$. The inventory increased from $6.0 \pm 0.6$ million moles in 1997 to $8.1 \pm 0.6$ million moles in 1999 and to $9.5 \pm 0.6$ million moles in 2001. CFC-11 inventory estimates were used to determine ULSW formation rates for different periods. For 1970-97, the mean formation rate resulted in $3.2-3.3 \mathrm{~Sv}\left(\mathrm{~Sv} \equiv 10^{6} \mathrm{~m}^{3} \mathrm{~s}^{-1}\right)$. To obtain this estimate, 5.0 million moles of CFC-11 located in 1997 in the ULSW in the subtropical/tropical Atlantic were added to the inventory of the subpolar North Atlantic. An estimate of the mean combined ULSW/LSW formation rate for the same period gave 7.6-8.9 Sv. For the years 1998-99, the ULSW formation rate solely based on the subpolar North Atlantic CFC-11 inventories yielded 6.9-9.2 Sv. At this time, the lack of classical LSW formation was almost compensated for by the strongly pronounced ULSW formation. Indications are presented that the convection area needed in 1998-99 to form this amount of ULSW exceeded the available area in the Labrador Sea. The Irminger Sea might be considered as an additional region favoring ULSW formation. In 2000-01, ULSW formation weakened to 3.3-4.7 Sv. Time series of layer thickness based on historical data indicate that there exists considerable variability of ULSW and classical LSW formation on decadal scales.
\end{abstract}

\section{Introduction}

The formation and spreading of the intermediate water masses of the subpolar North Atlantic Ocean, Labrador Sea Water (LSW) and the shallower Upper Lab-

Corresponding author address: Dagmar Kieke, Universität Bremen, Institut für Umweltphysik, Abt. Ozeanographie, OttoHahn-Allee, D-28359 Bremen, Germany.

E-mail: dkieke@physik.uni-bremen.de rador Sea Water (ULSW), have increasingly attracted interest over the past years. Both form the upper part of North Atlantic Deep Water (NADW) and thus contribute to the meridional overturning circulation, which is considered the driving mechanism for northward heat transport in the Atlantic Ocean.

The water mass known as ULSW has originally been detected by means of dominant tritium and chlorofluorocarbon signals (components CFC-11, CFC-12). These were measured in the tropical to midlatitude 
western North Atlantic during the 1970s-1980s (Jenkins and Rhines 1980; Weiss et al. 1985; Fine and Molinari 1988; Pickart 1992; Smethie 1993). At first, ULSW was identified as advected "classical" LSW (Weiss et al. 1985), which is that particular water mass formed in the interior Labrador Sea during strong wintertime convection (e.g., Lazier 1973; Clarke and Gascard 1983; Lab Sea Group 1998; Marshall and Schott 1999). Classical LSW can be tracked throughout the subpolar North Atlantic (SPNA) by minima in potential vorticity and salinity as well as a maximum in chlorofluorocarbon (CFC) (Talley and McCartney 1982; Rhein et al. 2002). Fine and Molinari (1988), however, suggested ULSW is a lighter version of classical LSW or Subpolar Mode Water because of its warmer temperatures in comparison with LSW. Pickart (1992) analyzed salinity-poor and CFC-rich water in the upper part of the deep western boundary current (DWBC) in the region between $70^{\circ}$ and $55^{\circ} \mathrm{W}$ south of the Grand Banks of Newfoundland. He termed this water mass "shallow DWBC water" and presented the first evidence for its formation in the boundary current region of the southern Labrador Sea. In a subsequent study, Pickart et al. (1996) renamed this water mass upper LSW. The authors found ULSW in the southern Labrador Sea in newly generated submesoscale eddies that were embedded in the DWBC. These eddies moved equatorward but decayed within several months. Despite the eddy erosion downstream of the Grand Banks region, their influence on the DWBC was nevertheless clearly visible because of the deposition of high CFC concentrations into the upper DWBC. Pickart et al. (1996) noticed that differences between ULSW and classical LSW were chiefly determined by salinity, ULSW being the less saline and hence less dense water mass. They chose $\sigma_{\Theta}$ $=27.68-27.72 \mathrm{~kg} \mathrm{~m}^{-3}$ as an appropriate density range for ULSW. In a later study, Pickart et al. (1997) found coherence between ULSW being formed by wintertime overturning and the dynamics of the Labrador Current, which gave support to ULSW having its origin in the western boundary current system in the southern Labrador Sea. Southward advection out of the central Labrador Sea and mixing could not explain the resulting property distributions.

Based on a large-scale CFC dataset normalized to the year 1990, Smethie et al. (2000) traced the spreading of ULSW with focus on that portion that leaves the subpolar gyre into the subtropical western Atlantic. In extending these analyses, Smethie and Fine (2001) presented first estimates of the CFC-11 inventories and formation rates of the ULSW layer. For the Atlantic Ocean south of about $46^{\circ} \mathrm{N}$ they calculated an inven- tory of 4.2 million moles and a corresponding mean formation rate of $2.2 \mathrm{~Sv}\left(\mathrm{~Sv} \equiv 10^{6} \mathrm{~m}^{3} \mathrm{~s}^{-1}\right)$. These analyses of ULSW were based on data from the early and late 1980s and the early 1990s. This particular period was associated with the occurrence of strong and deep wintertime convection in the Labrador Sea, reaching down to more than $2000 \mathrm{~m}$ in the interior basin (Lazier et al. 2002). The strength of convective activity is supposed to be correlated to atmospheric variability. It can be expressed in terms of the North Atlantic Oscillation (NAO) index (e.g., Hurrell 1995). The first half of the 1990s showed very strong winters with the highest NAO indices ever recorded during the last 50 years. The conditions favoring deep convection, however, have changed throughout the 1990s (Lazier et al. 2002).

From hydrographic and CFC-12 data sampled in the central Labrador Sea during summers 1991-2000, Azetsu-Scott et al. (2003) generated property time series for various intermediate- to deep-water masses. The authors reported on increasing CFC-12 concentrations in the classical LSW layer during 1991-94, which was due to the effect of the strong convective activity in this period. In the subsequent years the strongest increase was confined to the upper $1000 \mathrm{~m}$. For this newly ventilated layer, Azetsu-Scott et al. (2003) introduced the term "shallow LSW," which defines water in the density range $\sigma_{\Theta}=27.72-27.75 \mathrm{~kg} \mathrm{~m}^{-3}$.

Stramma et al. (2004) investigated the water mass spreading and variability in the western boundary current region of the SPNA during 1996-2001. Also Stramma et al. (2004) noticed the increasing formation of a water mass lighter than classical LSW. They used the term ULSW for water in the density range $\sigma_{\Theta}=$ $27.68-27.74 \mathrm{~kg} \mathrm{~m}^{-3}$ that makes up, to a large part, the shallow LSW of Azetsu-Scott et al. (2003) and the density range of the ULSW introduced by Pickart et al. $(1996,1997)$. The second half of the 1990s was a period of fairly weakened convection and shallower convection depths $(<1500 \mathrm{~m})$ (Lazier et al. 2002). Renewal of classical LSW had ceased, leading to an increased salinity and temperature and a decreased layer thickness. At the same time, the formation of the lighter ULSW intensified, and ULSW emerged as an increasingly thickening layer with a pronounced minimum of potential vorticity. Potential vorticity and CFC distributions suggest the central to northern Labrador Sea to be the formation region of this newly formed ULSW (Stramma et al. 2004). For the second half of the 1990s, ULSW, as analyzed by Azetsu-Scott et al. (2003) and Stramma et al. (2004), consequently appeared to be one mode that lies within a broad band of densities, associated with newly formed LSW. This suggests that there 
is an additional mechanism for ULSW formation that is not confined to the boundary current region as was proposed by Pickart et al. (1996, 1997).

Rhein et al. (2002, R02 hereinafter) highlighted the large-scale spreading of the classical LSW in the subpolar North Atlantic and estimated the corresponding CFC-11 inventory during 1997 (16.6 million moles) as a function of layer thickness and CFC-11 mean concentration. Based on these calculations, their mean LSW formation rate, representative for the period 1970-97, resulted in 4.4-5.6 Sv. Estimated high-NAO-index and low-NAO-index LSW formation rates were on the order of 8.1-10.8 and 1.8-2.4 Sv, respectively. Böning et al. (2003) analyzed LSW formation rates by applying the R02 CFC inventory method to an eddy-permitting ocean model with a horizontal grid resolution of $1 / 3^{\circ} \times$ $1 / 3^{\circ} \cos (\phi), \phi$ being latitude. The model was forced with monthly mean atmospheric fluxes based on a 3-yr climatology of European Centre for Medium-Range Weather Forecasts (ECMWF) analyses (Willebrand et al. 2001). Heat flux anomalies derived from the National Centers for Environmental Prediction (NCEP)National Center for Atmospheric Research (NCAR) reanalysis dataset (Kalnay et al. 1996) with respect to the period 1959-97 were superimposed on the climatological forcing fields. The model was suitable to reproduce the observed CFC distribution quite well. The modeled LSW formation rates calculated by the CFC inventory method (3.4-4.4 Sv) agreed well with the model's volumetric formation rate $(4.3 \mathrm{~Sv})$.

In the present study ULSW formation is estimated based on hydrographic and mainly CFC-11 data from three large-scale field campaigns carried out in 1997, 1999, and 2001. The methodology used throughout this study follows R02. The aim of this work is to derive CFC-11 inventory estimates of ULSW for the subpolar North Atlantic, to quantify changes in its formation, and to investigate the correlation of the layer thickness of ULSW in comparison with the thickness of classical LSW. Another focus is on the spreading of ULSW away from its source region in comparison with the spreading pathways of LSW. We present indications that the Irminger Sea might favor the local formation of ULSW.

\section{Data and applied methods}

\section{a. Chlorofluorocarbon and hydrographic data}

The dataset used in this study covers the years 1997, 1999, and 2001. The location of the particular cruises is displayed in Fig. 1, whereas details on the cruises are summarized in Table 1. The bulk of the CFC and CTD
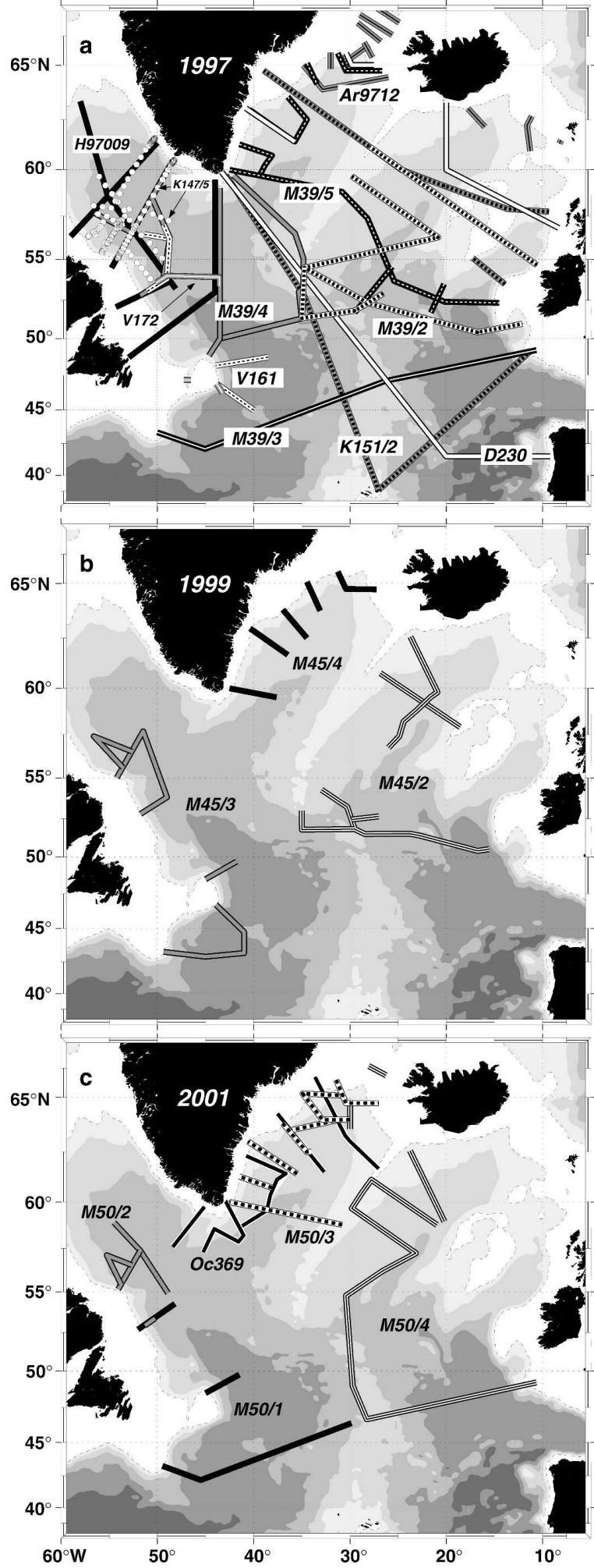

FIG. 1. Location of CTD and CFC-11 sections sampled during (a) 1997, (b) 1999, and (c) 2001. Bathymetric contours are given every $1000 \mathrm{~m}$. Stippled lines denote the 1000-m contour. Inserted labels indicate particular cruises as listed in Table 1. 
TABLE 1. CFC measurements carried out during 1997, 1999, and 2001. Rhein et al. (2002) added sections from 1996 and 1998 to their dataset of 1997 to improve the resolution in the boundary current region of the western North Atlantic. For reasons of consistency with Rhein et al. (2002), these are also included here in the fields of 1997. The location of all particular cruises is presented in Fig. 1. The abbreviations are PI: Principal Investigator, BIO: Bedford Institute of Oceanography, IFMK: Institut für Meereskunde, IUP: Institut für Umweltphysik, LDEO: LamontDoherty Earth Observatory, SIO: Scripps Institution of Oceanography, NOCS: National Oceanography Centre, Southampton, and Ugot: University of Gothenburg.

\begin{tabular}{|c|c|c|c|c|}
\hline & Cruise & Date & PI CFCs & Institution \\
\hline \multirow[t]{11}{*}{1997} & K147/5 & 7 Feb-12 Mar 1997 & Smethie & LDEO \\
\hline & $\mathrm{M} 39 / 2$ & 15 May-8 Jun 1997 & Rhein & IFMK \\
\hline & H97009 & 9 May-11 Jun 1997 & Jones & $\mathrm{BIO}$ \\
\hline & $\mathrm{K} 151 / 2$ & 30 May-2 Jul 1997 & Weiss & $\mathrm{SIO}$ \\
\hline & M39/3 & 13-30 Jun 1997 & Roether & IUP \\
\hline & M39/4 & 7 Jul-8 Aug 1997 & Rhein & IFMK \\
\hline & Ar9712 & 5 Aug-25 Sep 1997 & Tanhua & UGot \\
\hline & $\mathrm{D} 230$ & 7 Aug-17 Sep 1997 & $\begin{array}{l}\text { Smythe- } \\
\text { Wright }\end{array}$ & NOCS \\
\hline & M39/5 & 14 Aug-14 Sep 1997 & Rhein & IFMK \\
\hline & V161 & 19 Jul-16 Aug 1996 & Rhein & IFMK \\
\hline & V172 & 04 Jul-08 Aug 1998 & Rhein & IFMK \\
\hline \multirow[t]{3}{*}{1999} & M45/2 & 11 Jun-08 Jul 1999 & Rhein & IFMK \\
\hline & M45/3 & 11 Jul-10 Aug 1999 & Rhein & IFMK \\
\hline & M45/4 & 14-26 Aug 1999 & Rhein & IFMK \\
\hline \multirow[t]{5}{*}{2001} & M50/1 & 8-31 May 2001 & Rhein & IUP/IFMK \\
\hline & M50/2 & 2-18 Jun 2001 & Rhein & IUP/IFMK \\
\hline & M50/3 & 21 Jun-15 Jul 2001 & Rhein & IUP/IFMK \\
\hline & M50/4 & 17 Jul-12 Aug 2001 & Rhein & IUP/IFMK \\
\hline & Oc369 & 2-27 Aug 2001 & Smethie & LDEO \\
\hline
\end{tabular}

data has been compiled within the framework of the German program Sonderforschungsbereich 460 (SFB 460), entitled "Dynamics of Thermohaline Circulation Variability." The remaining data, if not provided by the authors, have been obtained from the World Ocean Circulation Experiment (WOCE) Hydrographic Program Office (WHPO). The main focus of the present study is on CFC-11 analysis, though the methods illustrated in the following also hold for CFC-12 data.

The CFC-11 data of 1997 (Fig. 1a) have already been analyzed with respect to classical LSW by R02 and are described therein. In the present study, CFC-11/CTD data from two cruises have been added (cruise Ar9712 close to the Greenland-Scotland Ridge as well as cruise H97009 in the central Labrador Sea). R02 quality controlled the CFC-11 dataset of 1997 for regions west of $32.5^{\circ} \mathrm{W}$. For the density range $27.77 \mathrm{~kg} \mathrm{~m}^{-3}<\sigma_{\Theta}<$ $27.79 \mathrm{~kg} \mathrm{~m}^{-3}$ they considered all samples that fell into a narrow temperature and salinity range $\left(\Theta \pm 0.003^{\circ} \mathrm{C}\right.$, $S \pm 0.003)$. This density range is regarded as not being affected by deep convection after 1995. Changes in the
CFC-11 concentration should therefore remain small. The mean rms error of CFC-11 concentrations in the considered density range varied from $2.5 \%$ to $3 \%$ for individual cruises (see R02 for details). The mean rms error for the complete dataset of 1997 used here resulted in $5.1 \%$; that is, the CFC-11 data from the different cruises are comparable within this percentage. For the 1999 data (Fig. 1b, Table 1), the mean CFC-11 rms varied from $0.5 \%$ to $2.1 \%$ for the individual cruises and $3.3 \%$ for the complete dataset. In 2001, the cruises M50/1-2 (Fig. 1c, Table 1) exhibited anomalous high CFC-11/CFC-12 ratios. A comparison of all CFC-11 and CFC-12 samples from 2001 showed that the CFC11 concentrations measured during M50/2 and to a lesser extent during M50/1 were too high. Despite this shortcoming, the combined dataset of 2001 showed conformity within $5.2 \%$ for all five cruises, while the mean rms of CFC- 11 for single cruises ranged from $1.8 \%$ to $3.4 \%$. Nevertheless, the dataset of 2001 has been corrected by reducing the CFC-11 data of M50/1 by $1 \%$ and $\mathrm{M} 50 / 2$ by $5 \%$. All CFC concentrations are given on the SIO-93 scale (Cunnold et al. 1994).

As for the CFC data, most of the CTD data are from SFB 460 and WHPO. CTD data from the Irminger Sea are to some part provided by the European Unionfunded programs Variability of Exchanges in the Northern Seas (VEINS) and Arctic-Subarctic Ocean Fluxes (ASOF), carried out by the Institut für Meereskunde Hamburg, Germany (courtesy of J. Meincke 2004, personal communication). The CTD data from late winter 1996/97 (K147/5) are obtained from the Labrador Sea Convection Experiment data repository (Krahmann et al. 2003). The accuracies of the SFB 460 CTD data were $0.002-0.004$ for salinity and $0.002^{\circ}-0.003^{\circ} \mathrm{C}$ for temperature (Schott et al. $1999 \mathrm{~b}$, 2000, 2002). Accuracies of the remaining cruises were similar.

The dataset from 1997 is probably one of the best ever resolved. The Irminger Sea has the best horizontal and vertical data coverage in 1997-2001, followed by the Labrador Sea (Fig. 1). Unfortunately, large areas in the central and eastern SPNA have not been sampled during 1999 and 2001. For example, we do not have any CTD/CFC profiles east of $40^{\circ} \mathrm{W}$ and south of $50^{\circ} \mathrm{N}$ in 1999. While the data coverage in 2001 was better relative to 1999 , considerable gaps remain. This is a problem that we deal with in detail in this study.

\section{b. Gridded fields}

Following Stramma et al. (2004) and R02, we define ULSW formed during the late 1990s as water in the density range $\sigma_{\Theta}=27.68-27.74 \mathrm{~kg} \mathrm{~m}^{-3}$, whereas the classical LSW is defined as $\sigma_{\Theta}=27.74-27.80 \mathrm{~kg} \mathrm{~m}^{-3}$. 
The vertical distance between the corresponding two isopycnals represents the layer thickness of either ULSW or LSW. These estimates have been derived from all available hydrographic profiles in all particular years.

Most of the profiles have more than two CFC observations in the ULSW layer. In 1997, ULSW is represented by only one CFC- 11 sample in 280 out of 606 profiles. The positions of these profiles are spread throughout the subpolar North Atlantic. In 1999, the number of profiles having one sample within the ULSW layer is 70 out of 164 profiles. Most of them are located on the continental slope in the Irminger Sea as well as in the Newfoundland Basin. In 2001, only 87 out of 285 profiles have less than two samples within the ULSW layer. The majority of these profiles are found above ridges like the Mid-Atlantic Ridge (MAR) and its northward extension, the Reykjanes Ridge. Average CFC-11 concentrations for the ULSW layer have been estimated by calculating the vertical distance-weighted average of all samples locally taken within the ULSW layer. This is termed "depth weighting."

In a second step, data from the particular years have been mapped on a common regular grid by applying a topography-following covariance function similar to that being introduced and described in detail by Davis (1998). This technique has been utilized widely to map float data (e.g., Davis 1998; Lavender et al. 2000, 2002; Fischer and Schott 2002). R02 compared the large-scale spreading of classical LSW in the subpolar North Atlantic by means of floats and CFC-11. They presented evidence that such a mapping scheme is suitable to be applied to CFC data as well. The CFC distribution of the classical LSW is controlled by topography and mainly follows contours of barotropic potential vorticity $f / H$ ( $f$ : Coriolis parameter; $H$ : water depth).

We have used the topography-following mapping algorithm as described by R02 to be consistent with their analysis. To summarize the main features: For every grid point of a smoothed version of the ETOPO5 bathymetry dataset water depths are derived to calculate the barotropic potential vorticity $f / H$. The spatial grid resolution is $0.5^{\circ}$ longitude $\times 0.25^{\circ}$ latitude. A generalized distance $r$ between observation locations and grid points is introduced. It depends on horizontal separation as well as differences in potential vorticity, both being divided by a scaling factor. The exact formulation is

$$
r^{2}=\frac{|a-b|^{2}}{\Lambda}+\frac{1}{\Phi} \frac{\left|\frac{f}{H}(a)-\frac{f}{H}(b)\right|^{2}}{\left(\frac{f}{H}\right)^{2}(a)+\left(\frac{f}{H}\right)^{2}(b)}
$$

with $a$ and $b$ being the position of grid points and those of the measurements; $\Lambda$ and $\Phi$ are the scaling parameters. The Gaussian covariance function $F$ to weight the data is of the form

$$
F(r)=\exp \left(-r^{2}\right)
$$

R02 give values for $\Lambda$ and $\Phi$, but these have to be rectified. The correct values, which have actually been used by R02, must be $1 / \Lambda=0.5 \times 10^{-4}\left(\mathrm{~km}^{-2}\right)$ and $1 / \Phi=100$ (dimensionless). These scaling parameters are also applied here and result from the following reasoning: In the original notation given by Davis (1998), $\Lambda$ is related to a typical horizontal correlation length scale $(\lambda)$ via the expression $\Lambda=2 \lambda^{2}$; $\Phi$ refers to the scale of decorrelation $(\phi)$ produced by the change in potential vorticity via $\Phi=\phi^{2} ; \lambda$ was set to $100 \mathrm{~km}$, which is a typical length scale in the boundary current regime. The choice of $\Phi=100$ (i.e., $\phi=10$ ) matches a depth difference of $150 \mathrm{~m}$ in the second term of Eq. (1).

The subpolar North Atlantic is subdivided into different regions to estimate regional changes and contributions to the CFC-11 inventory. These are the Labrador Sea, the Irminger Sea, the Newfoundland Basin, and the residual region east of the MAR, here named collectively Eastern Basin. The latter comprises the Iceland Basin, the Rockall Trough, and the West European Basin (WEB). Corresponding limits are displayed in Fig. 2.

\section{c. Salinity-CFC-11 correlation}

From oceanographic measurements carried out during 1964-74 at Ocean Weather Station Bravo in the central Labrador Sea, Lazier (1980) and Lazier et al. (2002) noticed that the surface layers are less saline than the underlying water masses. The annual cycle of salinity found in the upper $100 \mathrm{~m}$ of the water column showed the strongest decrease of salinity during summer. This is related to an advection of low salinity waters from the Labrador Current that is influenced by sea ice melting and freshwater runoff. The years with the strongest decrease in salinity (1967-71) coincided with a period of shallow wintertime convection (100$200 \mathrm{~m}$ ). Lazier (1980) attributed this to anomalous fresh and cold waters of Arctic origin being increasingly advected into the Labrador Sea via the West Greenland and Labrador Currents, thus further diluting the surface layer. In another study, Häkkinen (2002) analyzed 50 years of summer surface salinity in the region $45^{\circ}$ $55^{\circ} \mathrm{N}, 55^{\circ}-50^{\circ} \mathrm{W}$. From these observations she found indications of a large freshening in the mid- to late 1990s. The salinity time series presented by Azetsu- 


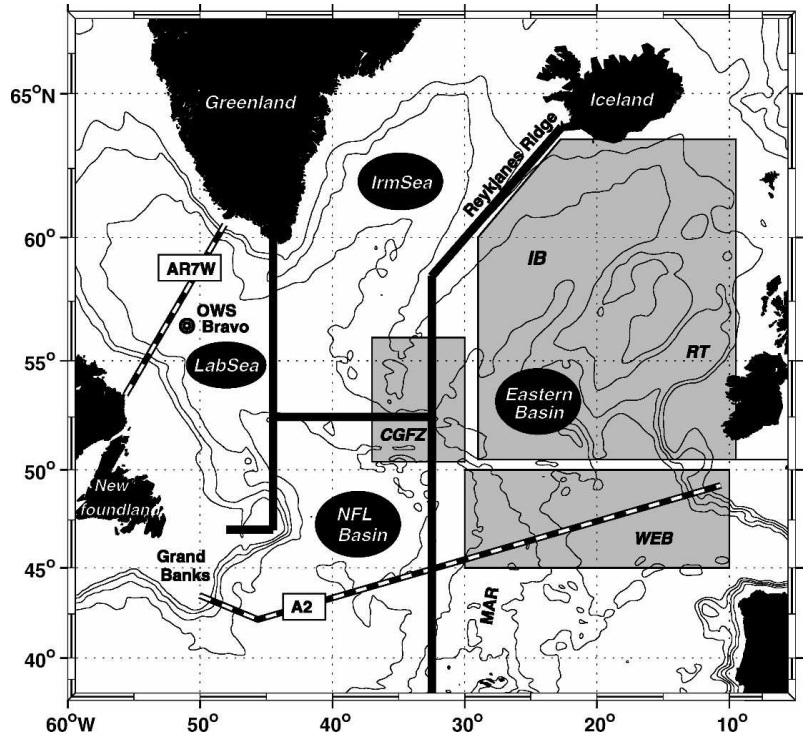

FIG. 2. Location of different basins of the subpolar North Atlantic. Irminger Sea (IrmSea), Labrador Sea (LabSea), Newfoundland Basin (NFL-Basin), and Eastern Basin. See text for further abbreviations. Thick lines mark area limits used to estimate regional contributions to the CFC-11 inventory. Shaded areas denote regions (IB/RT, CGFZ, WEB) discussed in detail in section 3. Dashed lines indicate the course of WOCE lines AR7W and $\mathrm{A} 2$.

Scott et al. (2003) for the period 1991-2000 from the central Labrador Sea also point to surface layers that are, in general, less saline than the underlying water mass layers.

The solubility of CFCs favors low salinity and cold conditions (Warner and Weiss 1985). An uptake of CFCs through gas exchange is more efficient for surface water masses that match these conditions. During convection that results in ULSW formation the water column is not mixed as deep as during convection that leads to the formation of classical LSW. Lazier et al. (2002) noted that during 1990-93 the deepening mixed layers penetrated into the saline deep-water masses underlying the LSW, thus increasing the salinity in the LSW from below. Therefore, ULSW carries high CFC concentrations that are higher and salinities that are lower than in the underlying classical LSW.

Figure 3 shows the CFC- 11 distribution versus salinity for different regions of the SPNA. Throughout the years, there is a shift to higher CFC-11 concentrations associated with higher salinities. In most regions both properties are strongly correlated. This is most pronounced in the western North Atlantic (Labrador Sea, Irminger Sea, and Newfoundland Basin). There the water with the lowest salinities shows the highest CFC concentrations. In the Eastern Basin, however, some deviations from this correlation are found. They refer to those regions where different water masses are present. For example, most profiles presented in Fig. 3b are from the Iceland Basin where ULSW mixes with Iceland-Scotland overflow water (ISOW). It enters the eastern North Atlantic by crossing the IcelandScotland Ridge, thus explaining the elevated CFC-11 values that coincide with high salinities.

The influence of Mediterranean Water (MW) is visible in the West European Basin (WEB: Fig. 3f). Mediterranean Water carries low CFC concentrations and is very saline $(S>35 \mathrm{psu})$. Relative to 1997 , data along WOCE section A2 $\left(\sim 48^{\circ} \mathrm{N}\right)$ show slightly increased CFC-11 concentrations in 2001 in the regions west of $20^{\circ} \mathrm{W}$.

The overall good correlation of ULSW salinities with CFC concentrations as well as the horizontal distributions led us to the conclusion that almost all CFCs are introduced into the ULSW layer by convection in the western subpolar North Atlantic.

\section{Spreading of ULSW}

\section{a. A large-scale view}

To better address regional differences and changes throughout the subsequent years, we have plotted horizontal property maps using the gridding algorithm described in section $2 \mathrm{~b}$. Figure 4 shows the CFC- 11 distribution of ULSW for the years 1997, 1999, and 2001, while Fig. 5 shows the corresponding layer thickness. Since the data resolution of the latter two years is coarser than in 1997, tracing relevant hydrographic features is, in fact, regionally confined.

The pronounced CFC-11 maximum $(>4.7$ pmol $\mathrm{kg}^{-1}$ ) located in the western to central Labrador Sea, shown in Fig. 4, is the most conspicuous feature of all presented tracer distributions. Except in 1997, it is located in the region of the greatest layer thickness. Some of the 1997 profiles show the highest concentrations observed in period 1997-2001 (cf. Fig. 3). To a certain part, these particular profiles are from the winter cruise included in our analysis. If the selected winter profiles are dismissed in the gridded CFC-11 field of 1997, the spatial pattern in Fig. 4 slightly changes. The large-scale maximum in the interior Labrador Sea is, however, maintained, which points to a slow leakage out of the interior Labrador Sea. The increase in CFC-11 between the particular years is about $0.1 \mathrm{pmol} \mathrm{kg}^{-1}$.

The far greater change is in the thickness of the ULSW layer (Fig. 5). The layer thickness considerably increased throughout the observed period. While in 1997 the maximum of the layer thickness (500-600 m) was confined to the western and northern boundary of 

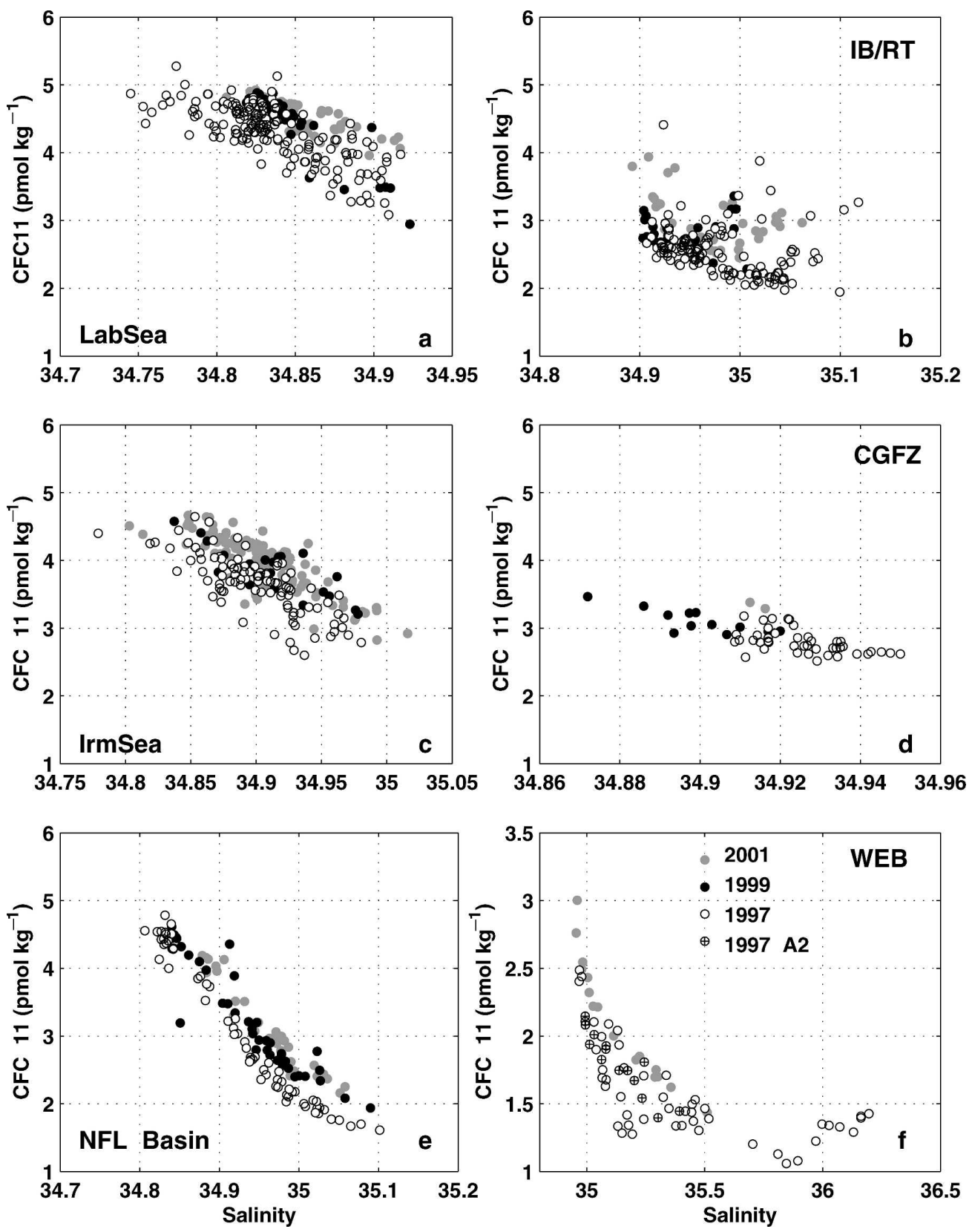

FIG. 3. Salinity-CFC-11 correlation for all samples taken within the ULSW layer. Shown are the years 1997 (white dots), 1999 (black dots), and 2001 (gray dots), displayed for different geographical regions: (a) LabSea, (b) IB/RT, (c) IrmSea, (d) CGFZ, (e) NFL Basin, and (f) WEB [along WOCE A2 section (A2)]. Please note the differing scales of axes. The location of profiles used in (b), (d), and (f) is indicated in Fig. 2 by gray-shaded areas.

the Labrador Sea, it was shifted in subsequent years to the central Labrador Sea, having almost doubled in 2001. The characteristics of the 1997 layer thickness distribution are completely attributed to the impact of the summer data. A recalculation of the corresponding field without the winter data did not show any significant difference.
We cannot state whether the layer thickness maximum observed in 1997 in the northern boundary current region of the Labrador Sea was also present in 1999 and/or 2001 since we do not have any data from the boundary current region north of about $56^{\circ} \mathrm{N}$. In any case, the Labrador Sea was found to be the most important area for the calculation of CFC inventories. 

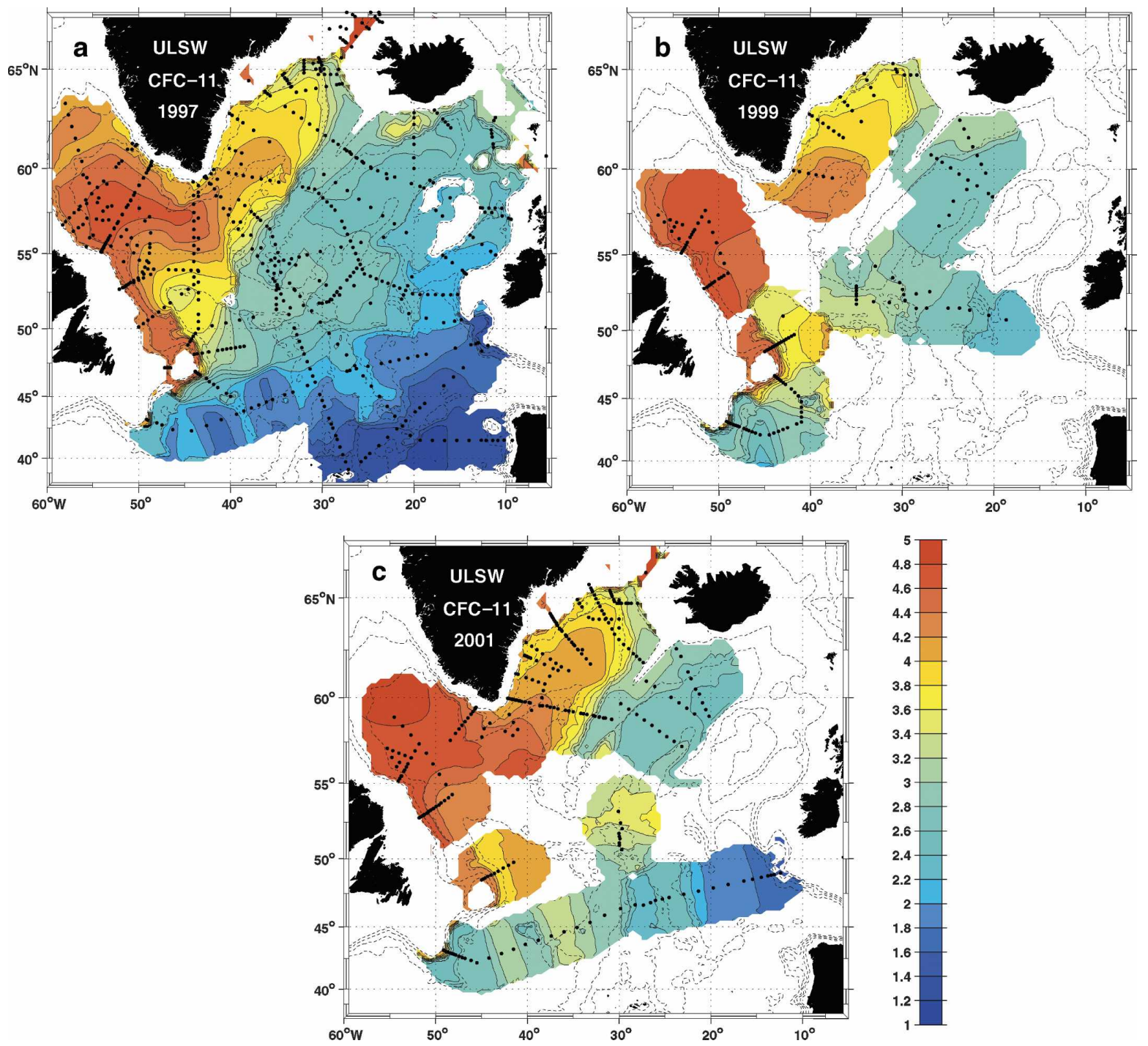

FIG. 4. CFC-11 (pmol kg ${ }^{-1}$ ) distribution in the ULSW during (a) 1997, (b) 1999, and (c) 2001. CFC-11 concentrations are layer averages derived as described in section $2 \mathrm{~b}$. Bathymetric contours are given every $1000 \mathrm{~m}$.

Throughout 1997-2001 the layer thickness increase outside the Labrador and Irminger Seas was only 200$400 \mathrm{~m}$.

From the Labrador Sea, the CFC-11 maximum with concentrations greater than 4.4 pmol kg-1 spread southward within the western boundary current system during all years. In 2001, Stramma et al. (2004) could not trace the spreading of the 2000 ULSW vintage out of the Labrador Sea farther than $53^{\circ} \mathrm{N}$, indicating a rather slow spreading time. This is indeed visible in the large-scale distribution of 2001 (Fig. 4), which shows CFC-11 > 4.6 pmol kg-1 confined to about $53^{\circ} \mathrm{N}$.

At the southern exit of the Newfoundland Basin $\left(\sim 43^{\circ} \mathrm{N}\right)$ the signal of increased CFC-11 is confined to the shelf break. The layer thickness appears to be simi- lar during all displayed years (200-300 m). Two to three stations of the 1999 and 2001 distribution closest to shore indicate higher values of up to $400 \mathrm{~m}$. Because of the small-scale nature of this feature, it is, however, hardly visible in the large-scale distribution of layer thickness (Fig. 5). The offshore part next to the boundary current is dominated by the strong and deepreaching North Atlantic Current (NAC). It carries different water masses than the ones present within the DWBC (Schott et al. 2004). From the analysis of LSW extremes determined from historical data, Koltermann et al. (1999) noticed a southward export path for LSW close to the western side of the MAR at about $37^{\circ}-$ $35^{\circ} \mathrm{W}$. Similar pathways have also been identified by profiling floats deployed during 2001 within the LSW 

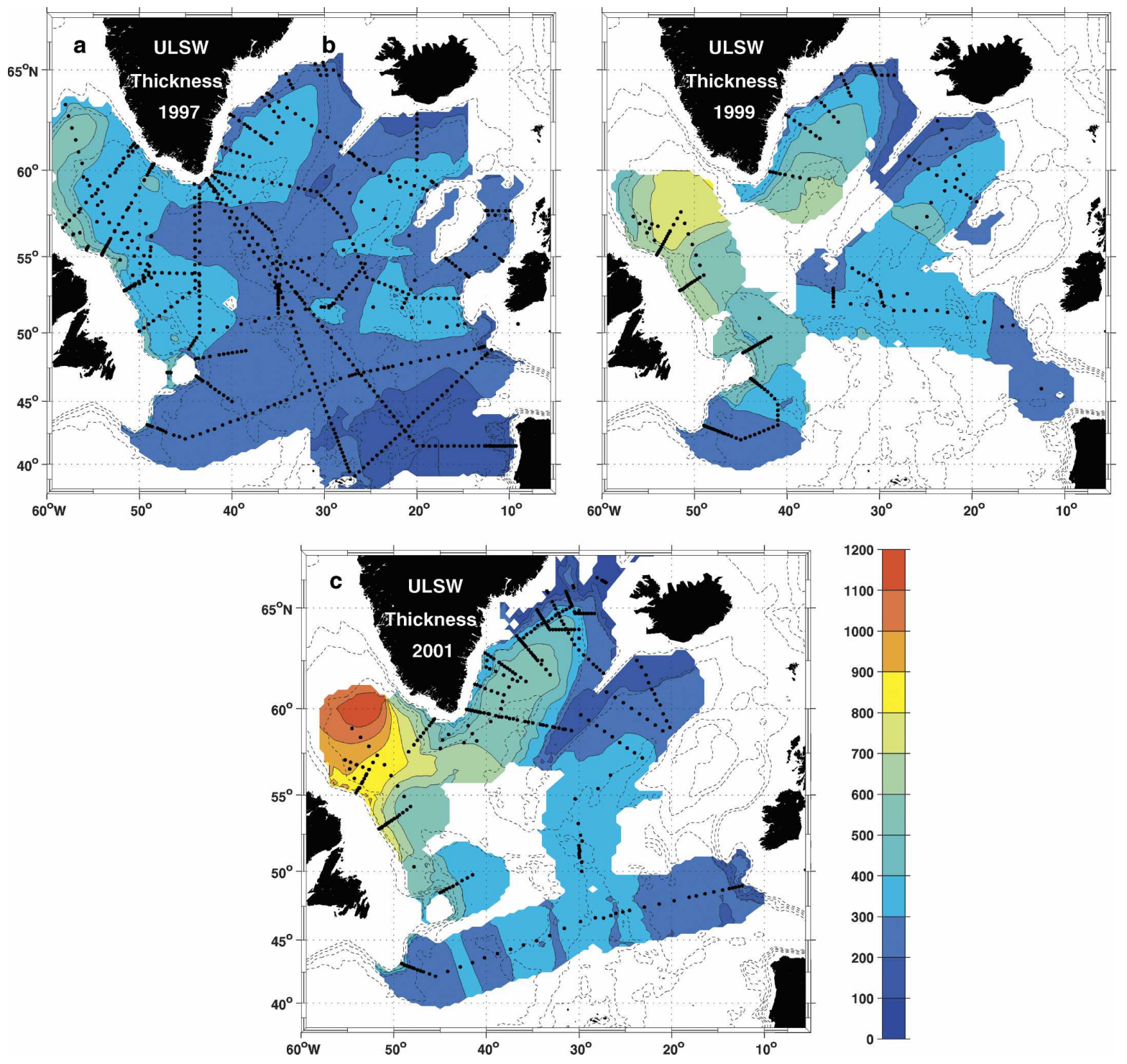

FIG. 5. Layer thickness (m) of ULSW for (a) 1997, (b) 1999, and (c) 2001. Bathymetric contours are given every $1000 \mathrm{~m}$.

(Schott et al. 2004). The floats have to spend some time at the surface to transmit their data to the satellite system. Corresponding trajectories, therefore, do not indicate a true Lagrangian spreading. However, in 2001, we observed increased CFC-11 signals in the ULSW outside the western boundary similar to the location proposed by Koltermann et al. (1999). These signals are associated with an increased layer thickness of more than $300 \mathrm{~m}$. For 1999, we do not have any data east of $40^{\circ} \mathrm{W}$.

Freshly ventilated CFC-rich ULSW seems also to invade the Irminger Sea. While there is only a small ribbon of CFC-11 concentrations greater than $4.2 \mathrm{pmol}$ $\mathrm{kg}^{-1}$ south of Greenland in 1997, increased concentrations of 4.3 and $4.5 \mathrm{pmol} \mathrm{kg}^{-1}$ are found during the following years in the southern Irminger Sea. Profiles in Denmark Strait indicate CFC-11 and salinity concentrations of similar magnitude as found in the Labrador Sea but with reduced layer thickness (about 100-200 m). From an extensive Denmark Strait survey Girton et al. (2001) estimated that the Denmark Strait overflow water (DSOW) descends from $500 \mathrm{~m}$ at sill depth to $1500 \mathrm{~m}$ at $200 \mathrm{~km}$ farther downstream. The ULSW layer south of Denmark Strait is found in the 1997 data at about $800-1000 \mathrm{~m}$. We cannot neglect stirring of water masses due to entrainment and eddies present in the Irminger Sea (Krauss 1995). This process is, however, assumed to be constant and does not affect the differences in the inventories between the years. The gradients of the CFC-11 and layer thickness distributions 
point to the western SPNA being the far more important source for the high CFC-11 signals in the ULSW layer.

There has not yet been any investigation concerning the spreading of ULSW into the eastern North Atlantic Basin with respect to the CFC data from the late 1980s/ early 1990s. Smethie et al. (2000) and Smethie and Fine (2001) traced that ULSW portion leaving the subpolar gyre and focused on spreading to subtropical and tropical latitudes rather than spreading within the subpolar gyre. The data from 1997 to 2001, however, indicate that lenses of the recently formed ULSW have crossed the MAR, presumably through the Charlie Gibbs Fracture Zone (CGFZ, $\left.52.5^{\circ} \mathrm{N}, 32^{\circ} \mathrm{W}\right)$. A CTD profile from 2001 , located in the northern channel of the CGFZ at $30^{\circ} \mathrm{W}$, indicated a pronounced $\mathrm{O}-\mathrm{S}$ minimum in the ULSW (not shown here) that was associated with the highest CFC-11 concentrations in the ULSW layer in this region. Alhough small-scale features at single stations cannot properly be resolved in our horizontal maps, Fig. 4 nevertheless exhibits CFC-11 concentrations east of the MAR at $30^{\circ} \mathrm{W}$ in 2001 that are increased relative to previous years. This points to ULSW that has entered the Eastern Basin through CGFZ. If we assume that this signal found in summer 2001 has been generated in the Labrador Sea in late winter 2000, ULSW would have taken about $1.5 \mathrm{yr}$ to reach the eastern CGFZ, flowing at an estimated spreading rate of $5 \mathrm{~cm} \mathrm{~s}^{-1}$. Velocity measurements by Schott et al. (1999a) and float results from Lavender et al. (2000) as well as Bower et al. (2002) indicate that the CGFZ is an important gateway for middepth water masses from the Labrador Sea to enter the eastern North Atlantic Ba$\sin$. The floats analyzed by Lavender et al. (2000) were ballasted to drift at 700-m depth. On average, they needed 1.6-2.6 yr to reach the Iceland Basin and drifted at an average subsurface speed of $8.7 \mathrm{~cm} \mathrm{~s}^{-1}$. Although, again, this does not indicate a true Lagrangian spreading, this estimate is at least comparable to ours.

The salinity-CFC-11 correlation (Fig. 3f) indicated the presence of saline, CFC-poor Mediterranean Water in the West European Basin. The lowest CFC-11 concentrations were found close to the European shelf accompanied by the lowest-layer thickness (Figs. 4 and 5). Close to the MAR the concentrations and layer thickness increased. The circulation maps provided by Bower et al. (2002) and Lavender et al. (2000, 2005) indicate that the major flow enters the Eastern Basin via the fracture zones within the MAR and turns southward after a cyclonic loop. The observed increase in CFC-11 and layer thickness close to the MAR obviously is related to an intrusion of southbound ULSW after having entered the Eastern Basin rather than an increase of watermass properties in the Mediterranean Water. Thus, the ULSW of the late 1990s tends to follow similar pathways in the subpolar North Atlantic as have been revealed for the underlying classical LSW by various authors (e.g., Talley and McCartney 1982; Sy et al. 1997; Lavender et al. 2000; Rhein et al. 2002).

\section{b. Boundary region versus interior ocean}

During the WOCE and post-WOCE period (19902001) hydrographic sections were repeated annually along the WOCE line AR7W. From the western side of the Labrador Sea, this line crosses the Labrador Basin in a northeastern direction (cf. Fig. 2). Corresponding data from WHPO (cf. Lazier et al. 2002) and SFB 460 allow the analysis of layer thickness variability of ULSW as well as classical LSW (Fig. 6).

During the first half of the 1990s, LSW occupied the largest fraction of the water column. Layer thicknesses of more than $2000 \mathrm{~m}$ indicate a thick and homogeneous reservoir of LSW that was ventilated by the deep convection events of the early 1990s (e.g., Lilly et al. 1999; Lazier et al. 2002). The corresponding ULSW layer was rather thin (thickness $<200 \mathrm{~m}$ ). At the end of the 1990s, when deep convection has weakened, a remarkable increase in ULSW layer thickness is noted, accompanied by a decrease of LSW thickness. According to Lazier et al. (2002), this marks the phase when the Labrador Sea restratified. The shallow convection of that time, initiated by milder and warmer winters, was limited to about $1000 \mathrm{~m}$ and the classical LSW was correspondingly isolated from ventilation. The increased ULSW layer thickness has become more similar to the one of classical LSW. Section data presented by Stramma et al. (2004) indicate that the lower boundary limiting ULSW $\left(\sigma_{\Theta}=27.74 \mathrm{~kg} \mathrm{~m}^{-3}\right)$ has shifted to greater depths. ULSW that is low in salinity and high in CFCs and the salinity minimum of the LSW are separated by an intermediate salinity maximum at about $\sigma_{\Theta}=27.76 \mathrm{~kg}$ $\mathrm{m}^{-3}$. It indicates that transformation of LSW into the less dense ULSW through diapycnal mixing is negligible. The salinity maximum is present since 1997 and presumably results from the lateral admixture of saline Irminger Water into the LSW layer (Lazier et al. 2002). The convection of the late 1990s was not deep enough to erode it.

In contrast to the classical LSW, the ULSW shows much more variability in the boundary current in the Labrador Sea. Especially on the Canadian side, the layer thickness continuously increased throughout the years. On the Greenland side, however, this increase was delayed in time. The float analyses by Lavender et 

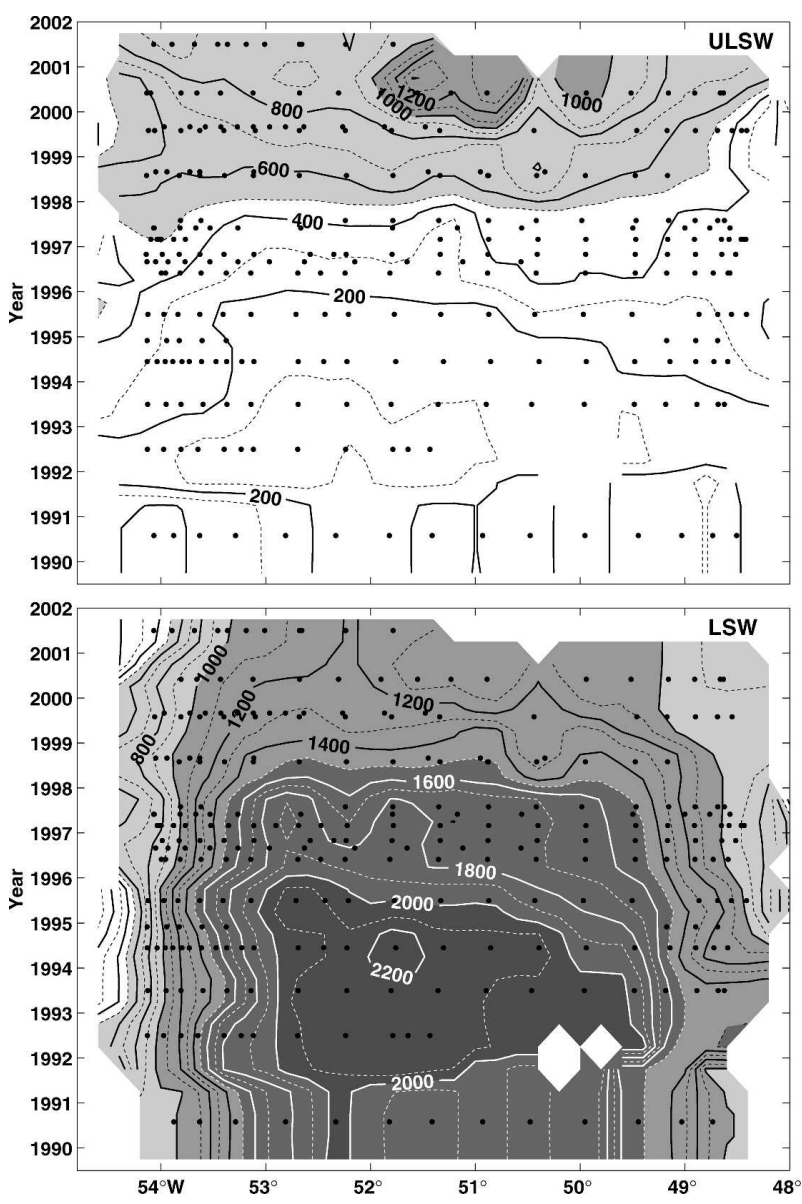

FIG. 6. Layer thickness (m) of (top) ULSW and (bottom) LSW for the period 1990-2001. Estimates are plotted as a function of time and longitude along WOCE line AR7W, which crosses the central Labrador Sea. The location of AR7W is shown in Fig. 2. Labeled years indicate the beginning of each year. Black dots mark the position of profiles. Layer thicknesses greater $500 \mathrm{~m}$ are shaded gray in intervals of $500 \mathrm{~m}$. Contours are given every $100 \mathrm{~m}$.

al. (2000) revealed the presence of several cyclonic circulation cells located close to the boundary currents of the Labrador Sea. Based on these results and further model studies, Straneo et al. (2003) discuss the existence of a new advective pathway present in the interior Labrador Sea. This so-called internal branch is supposed to be responsible for the recirculation of water masses from the interior basin to the Greenland coast. Alhough this particular branch has not been directly observed so far, Straneo et al. (2003) stress the importance of recirculation cells for the redistribution and storage of water masses. The residence time for LSW in the interior Labrador Basin is thus much longer (4-5 yr: Straneo et al. 2003) as opposed to the boundary current region (e.g., LSW takes about $1.5 \mathrm{yr}$ from $56^{\circ} \mathrm{N}$ to about $43^{\circ} \mathrm{N}$; Stramma et al. 2004).

\section{CFC-11 inventory variability of ULSW during 1997-2001}

\section{a. CFC inventories}

Following R02, the total CFC-11 inventory $\mathrm{CFC}_{\mathrm{INV}}$ of a water mass is calculated from the gridded fields of layer thickness and average CFC-11 concentration:

$$
\mathrm{CFC}_{\mathrm{INV}}=\rho \sum_{i j}\left(C_{i j} A D_{i j}\right),
$$

with $C_{i j}$, CFC-11 concentration ( $\mathrm{pmol} \mathrm{kg}{ }^{-1}$ ) at a particular location lat $(i), \operatorname{lon}(j) ; D_{i j}$, layer thickness (m) at location lat $(i), \operatorname{lon}(j) ; A$, area $\left(\mathrm{m}^{2}\right)$ of grid cell $\left(0.25^{\circ}\right.$ latitude $\times 0.5^{\circ}$ longitude); and $\rho$, density of water $(\mathrm{kg}$ $\mathrm{m}^{-3}$ ). The inventory $\mathrm{CFC}_{\mathrm{INV}}$ of ULSW is estimated for the SPNA between $40^{\circ}$ and $65^{\circ} \mathrm{N}$.

\section{b. Filling data gaps}

In the following, three methods have been applied to estimate the inventory of ULSW according to Eq. (3). They differ in treating the spatial resolution of the parameter fields.

Method 1 (referred to as "orig"): The layer-averaged CFC-11 and layer thickness of 1997, 1999, and 2001, have been gridded using the same correlation scales given in section $2 \mathrm{~b}$. The resulting inventories of 1999 and 2001 are severely underestimated, as can be recognized from the horizontal inventory distributions (Fig. 7, left column). Large areas of the SPNA are not resolved. As we are interested in the changes between the years, the CFC inventories of 1999 and 2001 cannot be estimated in the same way as the inventory of 1997.

Method 2 (referred to as "added \%"): At first, the inventory of 1997 estimated according to method 1 (orig) was artificially reduced. This was done by transferring the gaps present in the orig fields of 1999 and 2001 to the orig inventory of 1997. The 1997 inventory was recalculated with the data gaps of (i) 1999 and (ii) 2001. The result was compared with the full-coverage estimate (orig) of 1997. Differences indicate how much of the inventory is supposed to be missed in 1999 and 2001 because of fewer available data. This missing fraction (given in percentage) is added to the orig inventories of 1999 and 2001. The temporal change during the years is accounted for at those grid points being filled in the orig fields of 1999 and 2001. The most important regions are the Labrador and Irminger Seas, and these are quite well-covered by observations. In those regions with no data in the orig fields, the inventories resulting from the added-\% method are thus adjusted to the 1997 distribution to give at least a lower-limit estimate. 

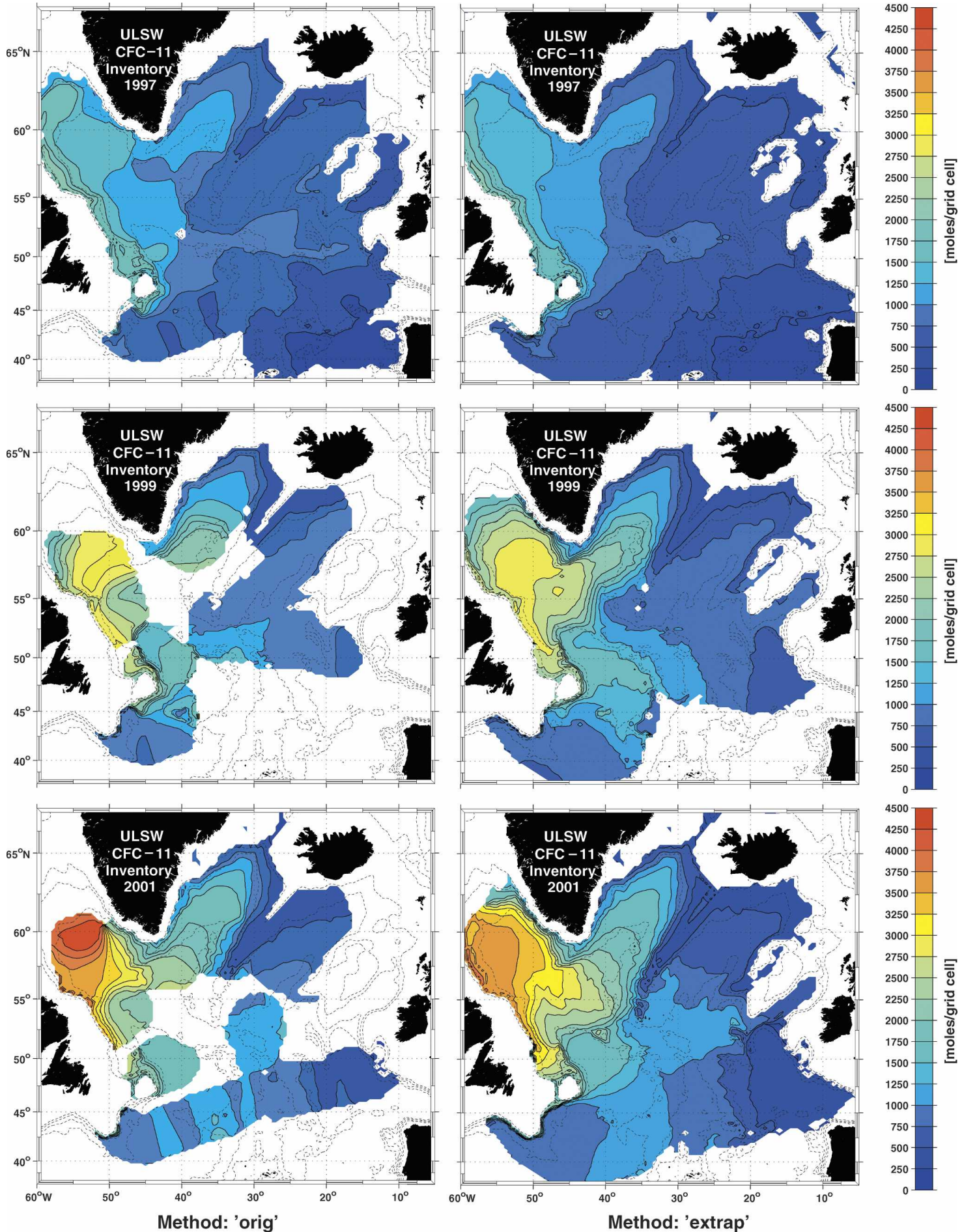

FIG. 7. Estimated CFC-11 inventory (moles per $0.5^{\circ} \times 0.25^{\circ}$ grid cell) of ULSW, based on the data distribution shown in Fig. 1: (top) 1997, (middle) 1999, and (bottom) 2001. (left) Results from method 1 (orig); (right) results from method 3 (extrap). Superimposed bathymetric contours are given every $1000 \mathrm{~m}$. 
TABLE 2. Estimated CFC-11 inventories of ULSW for the years 1997, 1999, and 2001. Orig represents the inventory using the horizontal scaling parameters according to Rhein et al. (2002), Added \% and Extrap denote estimates from either adding missing percentage fractions or changing the extra/interpolation of data. See text for details.

\begin{tabular}{|c|c|c|c|c|c|c|c|c|c|}
\hline \multicolumn{10}{|c|}{ CFC-11 inventory $\left(10^{6}\right.$ moles $)$} \\
\hline \multirow[b]{2}{*}{ Region } & \multicolumn{3}{|c|}{1997} & \multicolumn{3}{|c|}{1999} & \multicolumn{3}{|c|}{2001} \\
\hline & Orig & Added \% & Extrap & Orig & Added \% & Extrap & Orig & Added \% & Extrap \\
\hline Total SPNA & 5.6 & - & 6.0 & 5.3 & 8.4 & 8.1 & 6.8 & 9.4 & 9.5 \\
\hline LabSea & 1.7 & - & 1.7 & 2.0 & 3.1 & 2.8 & 2.9 & 3.8 & 3.5 \\
\hline IrmSea & 1.0 & - & 1.0 & 1.0 & 1.5 & 1.5 & 1.4 & 1.8 & 1.9 \\
\hline NFL Basin & 1.1 & - & 1.3 & 1.2 & 1.6 & 1.9 & 1.2 & 1.7 & 1.9 \\
\hline Eastern & 1.8 & - & 2.0 & 1.1 & 2.2 & 1.9 & 1.3 & 2.1 & 2.2 \\
\hline
\end{tabular}

This rather statistical analysis is opposed to a more physically based approach.

Method 3 (referred to as "extrap"): The advantage of the applied algorithm to map the data is the preservation of gradients at boundaries. R02 (their Fig. 6) present examples at various grid points where the influence of the weighting function is either isotropic (basin interior) or follows the topography (near topographic slopes). For the fields of 1999 and 2001, we have changed the horizontal scaling parameter given in Eq. (1) from $1 / \Lambda=0.5 \times 10^{-4}$ to $1 / \Lambda=0.1 \times 10^{-4}$. This results in a larger correlation length scale of $\lambda=224$ $\mathrm{km}$. A weight of $10 \%$ is considered at a distance of 480 $\mathrm{km}$. The gaps as seen, for example, in the central North Atlantic region (Fig. 4) are covered. The CFC-11 inventory fields of 1997, 1999, and 2001 that are recalculated according to this method are displayed in Fig. 7 (right column). The increased smoothing results in an erosion of peak values. On the other hand, higher concentrations/thicknesses are spread over a larger area.

\section{c. Assessing the uncertainties}

A statistical approach to estimate the uncertainty in the horizontal distribution of layer thickness, CFC-11 concentration, and the resulting inventory is known as jackknifing. A given dataset is subsampled by removing a fixed number of the available data points (Tichelaar and Ruff 1989). In their analysis on classical LSW during 1997, R02 used the jackknifing approach to randomly remove 50\% of all the data available in 1997. Then, they calculated the rms error of all parameters at all grid points from 100 different subsamples. The rms at each grid point indicates the degree of uncertainty in the property fields that is due to reduced data coverage (cf. Figs. 1a-c), nonsynopticity of the particular cruises (see Table 1), and measurement errors (see R02 for details). In the CFC 11 fields, the greatest rms error exceeding $10 \%$ was found in the Newfoundland Basin during all three years. In 2001, also the region $20^{\circ}-30^{\circ} \mathrm{W}$ in the WEB indicated increased uncertainties. The greatest uncertainty in the total CFC-11 inventory of the SPNA during 1997 amounted to \pm 0.6 million moles, if the inventory was estimated according to method 1 (orig). The jackknifing has been repeated with the 1997 inventory derived according to method 3 (extrap). Here the resulting rms of the total ULSW inventory in the SPNA amounted to \pm 0.5 million moles. Because of the limitations of the applied methodology and assumptions made, the greater error of \pm 0.6 million moles is considered as more appropriate.

\section{d. Inventory estimates of ULSW}

The inventory estimates are summarized in Table 2. In the SPNA between $40^{\circ}$ and $65^{\circ} \mathrm{N}$, the total CFC- 11 inventory of ULSW during 1997 is calculated to $6.0 \pm$ 0.6 million moles. Because of the altered correlation scale the SPNA inventory of 1997 derived from the different methods increased from 5.6 million to 6.0 million moles, that is, by $7 \%$. However, differences in the estimates of different methods cannot be distinguished since the inventory differences are within the error margins. For the year 1999, the SPNA inventory of ULSW is $8.1 \pm 0.6$ million moles and in $20019.5 \pm 0.6$ million moles. We do not have CFC-11 inventory estimates of ULSW for the subpolar North Atlantic prior to 1997 since Smethie and Fine (2001) excluded that region in their analysis. Therefore, we combine the ULSW inventory of the SPNA in 1997 with an estimate for the subtropical/tropical Atlantic in 1997 (D. A. LeBel et al. 2002, unpublished manuscript). The authors received 5.0 million moles for the Atlantic Ocean between $42^{\circ} \mathrm{N}$ and about $20^{\circ} \mathrm{S}$. As a result, the CFC-11 inventory of ULSW in the total Atlantic Ocean during 1997 yields 11.0 million moles.

To estimate the regional contributions to the total CFC-11 inventory, the subpolar North Atlantic has been subdivided into four different basins (cf. Fig. 2). Throughout the years, the western SPNA experienced 
TABLE 3. CFC-11 inventories of ULSW for the year 1997. SPNA: Subpolar North Atlantic, LabSea: Labrador Sea, IrmSea: Irminger Sea, and NFL Basin: Newfoundland Basin. Given percentages denote the regional contribution to the corresponding total layer inventory of the SPNA. See text for details.

\begin{tabular}{lcc}
\hline \hline \multicolumn{1}{c}{ Region } & $\begin{array}{c}\text { Inventory of } 1997 \\
\left(10^{6} \text { moles }\right)\end{array}$ & $\begin{array}{c}\text { Regional contribution } \\
(\%)\end{array}$ \\
\hline Total SPNA & $5.6 \pm 0.6$ & 100 \\
LabSea & $1.7 \pm 0.2$ & 30 \\
IrmSea & $1.0 \pm 0.1$ & 18 \\
NFL Basin & $1.1 \pm 0.1$ & 20 \\
Eastern Basin & $1.8 \pm 0.2$ & 32 \\
\hline
\end{tabular}

the greater CFC-11 concentrations as well as layer thicknesses, as has been pointed out in the previous section. This is reflected in the regional contributions to the total layer inventory of 1997 (Table 3). Two-thirds are found in the western North Atlantic (sum of LabSea, IrmSea, and NFL Basin), while the remaining third is located in the Eastern Basin. A similar regional partition has been estimated by R02 for the classical LSW in 1997.

The largest change occurred in the Labrador Sea. The inventory of this region more than doubled from 1.7 million moles in 1997 to 3.5-3.8 million moles during 2001, with the greater changes occurring during the first two years rather than the last (Table 2). The main reason is the increase in layer thickness which was stronger during 1997-99 than during 1999-2001 (Stramma et al. 2004).

The contribution of the Labrador Sea region to the total layer inventory increased from 30\% in 1997 to $35 \%-37 \%$ in 1999 and to $37 \%-40 \%$ in 2001 . Difference maps (not shown) of the corresponding layer thickness fields indicate that the ULSW layer thickness in the Labrador Sea north of about 55 ${ }^{\circ} \mathrm{N}$ increased from 1997 to 2001. Depending on the method, the Irminger Sea inventory increased from 1.0 million moles in 1997 by $80 \%-90 \%$ in 2001 . The change in the Newfoundland Basin is less, but still more than $45 \%$ of the 1997 inventory introduced in the subsequent two years, followed by a minor increase of about $12 \%$ from 1999 to 2001 (this is only resolved by method 3).

The changes in the inventory of the Eastern Basin are more difficult to assess. From 1997 to 1999 the inventory estimate of the Eastern Basin, calculated from adding missing percentage fractions, rose by 0.4 million moles $(+22 \%)$. During these years the Eastern Basin north of about $50^{\circ} \mathrm{N}$ experienced an increase in layer thickness of 50-100 m together with an increase in the CFC-11 concentration of up to $0.25 \mathrm{pmol} \mathrm{kg}^{-1}$, which both account for the inventory increase. In 1999 there was no sampling along WOCE line A2. Even the ad- justed extra and interpolation (method 3) could not cover well the southern part of the West European Basin (Fig. 7). This might explain the regional inventory decrease from 1997 to 1999 since an important part is still missed. Although this is improved in the gridded fields of 2001 (method 3), the southeastern WEB between $40^{\circ}$ and $43^{\circ} \mathrm{N}$ is not covered. The only available CFC-11 samples are from the WOCE line A2. Data to the south of it (as in 1997) do not exist.

\section{ULSW formation rates}

\section{a. Basic assumptions}

The formation rate of ULSW is considered as the transport of newly formed ULSW sinking across the isopycnal $\sigma_{\Theta}=27.68 \mathrm{~kg} \mathrm{~m}^{-3}$, which marks the upper boundary of the ULSW layer. The accumulation of CFC-11 within a water mass increases, starting at the time when CFCs were initially released into the atmosphere to present time. Following Orsi et al. (1999), this equals the current CFC-11 inventory minus a loss of CFC-11 out of the considered water mass and into overlying and/or underlying layers. From our previous findings we assume that all ULSW is formed by wintertime convection in the western subpolar North Atlantic. This process is believed to be by far the most important source for CFC-11 in the ULSW layer; that is, lateral mixing with other water masses of the same density is ignored as well as diapycnal mixing.

The atmospheric time history for CFC-11 is well known since its initial release to the atmosphere (Walker et al. 2000). With the solubility function depending on temperature and salinity (Warner and Weiss 1985) it can be expressed as the CFC-11 concentration that is in equilibrium to the atmosphere. The latter is given by the saturation level. With the combined CFC-11 inventory of the subpolar to tropical Atlantic (11.0 million moles), the annual mean formation rate of ULSW is estimated for the period 1930-97 as follows:

$$
R_{1}=\frac{\mathrm{CFC}_{\mathrm{INV}}\left(t_{n}\right)}{\rho \int_{t_{0}}^{t_{n}}\left[C_{\mathrm{eq}}(t) \times \mathrm{sat}\right] d t},
$$

with $R_{1}$, formation rate $(\mathrm{Sv})$; $\mathrm{CFC}_{\mathrm{INV}}$, estimated CFC11 inventory for ULSW; $C_{\mathrm{eq}}(t), \mathrm{CFC}-11$ concentration $\left(\mathrm{pmol} \mathrm{kg} \mathrm{kg}^{-1}\right)$ in water in year $t\left(t_{0}, \ldots, t_{n}\right)$ that is in equilibrium with the atmosphere [for atmospheric data see Walker et al. (2000)]; sat is the degree of saturation for newly formed ULSW.

Furthermore, we regard changes in the inventories among the years 1997, 1999, and 2001. Using the inven- 
tory estimates given in Table 2, Eq. (4) is therefore modified as follows:

$$
R_{2}=\frac{\mathrm{CFC}_{\mathrm{INV}}\left(t_{2}\right)-\mathrm{CFC}_{\mathrm{INV}}\left(t_{1}\right)}{\rho \int_{t_{1}}^{t_{2}}\left[C_{\mathrm{eq}}(t) \times \mathrm{sat}\right] d t} .
$$

Equation (5) is applied to the time periods 1998-99 and 2000-01 and gives corresponding formation rate estimates. Here, we consider the SPNA as a closed basin for these 2-yr-intervals. The new ULSW is assumed not to have yet left the subpolar gyre during this time. From analyses based on an advective-diffusive model, Straneo et al. (2003) inferred residence times for LSW in the Labrador Basin to be 4-5 yr. Stramma et al. (2004) estimated that LSW needs about $1-2$ yr to flow from its formation region to the Grand Banks at $43^{\circ} \mathrm{N}$ where it is exported to the south. ULSW formed during the late 1990s was found to spread at a similar spreading rate (about $2 \mathrm{yr}$ from $56^{\circ}$ to $43^{\circ} \mathrm{N}$ ). Our estimates from section 3 indicated about $1.5 \mathrm{yr}$ for ULSW to reach the CGFZ. Obviously, during two years the SPNA seems large enough to keep the bulk of the inventory. Nevertheless, Figs. 4, 5, and 7 indicate that an export to the south exists. Smethie and Fine (2001) estimated an ULSW inventory of 4.2 million moles for the year 1990 and for the Atlantic Ocean south of about $46^{\circ} \mathrm{N}$. In contrast, the subtropical/tropical CFC-11 inventory of ULSW based on data from 1997 gave 5.0 million moles south of $42^{\circ} \mathrm{N}$ (D. A. LeBel et al. 2002, unpublished manuscript). Although the considered regions and the ULSW layers defined by Smethie and Fine (2001) and D. A. LeBel et al. (2002, unpublished manuscript) for the subtropical to tropical Atlantic are different, a comparison of these results indicates at least that there is not a remarkable change from 1990 to 1997. As a first approximation it is therefore assumed that an export of ULSW out of the subpolar gyre is small within two years and can be neglected. Considering the SPNA as a closed box therefore seems appropriate.

Equations (4) and (5) show a dependency on the saturation level of CFC-11. Several investigations from the Labrador Sea show convected water masses exhibiting low CFC-11 saturations. They result from the time scale of convection, which is much smaller than the one for air-sea gas exchange (several days versus a month). Surface water exposed to the atmospheric input of CFC is transferred to deeper layers much more quickly than the time that air-sea gas exchange needs to bring the atmosphere and surface water into equilibrium. For the classical LSW, Wallace and Lazier (1988) and Smethie et al. (2000) found saturations in convected water of
$60 \%-70 \%$. Based on CFC data collected in late winter 1996/97, the analysis of R02 showed that, prior to convection, water located above LSW is saturated at $85 \%$. Since the water above the LSW will be transferred to LSW through convection and add its volume and its CFC content to the LSW inventory, R02 adopted this higher value as the more suitable one to calculate the formation rate.

For the ULSW layer of the 1980s/early 1990s, Smethie et al. (2000) estimated ULSW to be saturated at $70 \%$. Depth-weighted CFC-11 profiles with surface densities of $\sigma_{\Theta}>27.68 \mathrm{~kg} \mathrm{~m}^{-3}$ and $\sigma_{\Theta}<=27.74 \mathrm{~kg}$ $\mathrm{m}^{-3}$, sampled during February-March 1997 in the central Labrador Sea, showed mean CFC-11 concentrations of $4.59 \pm 0.11 \mathrm{pmol} \mathrm{kg}^{-1}$ in the upper $700 \mathrm{~m}$. Corresponding mean concentrations from profiles with surface densities smaller $\sigma_{\Theta}=27.68 \mathrm{~kg} \mathrm{~m}^{-3}$ were slightly decreased $\left(4.53 \pm 0.42 \mathrm{pmol} \mathrm{kg}^{-1}\right)$, indicating about $1.5 \%$ being added by air-sea gas exchange during active convection. Since throughout the considered years the summer isopycnal $\sigma_{\Theta}=27.68 \mathrm{~kg} \mathrm{~m}^{-3}$ was located at $\sim 200 \mathrm{~m}$ (cf. Fig. 2 in Stramma et al. 2004), CFC-11 concentrations of these profiles down to this depth average to $4.90 \pm 0.36 \mathrm{pmol} \mathrm{kg}{ }^{-1}$, which conforms with a saturation of $83.3 \% \pm 4.4 \%$. This is a water layer that is assumed to be converted to ULSW by the convection process. A combination of these estimates gives $85 \%$ saturation, which is identical to the R02 estimate for LSW.

\section{b. ULSW formation rates $1970-97$}

Stramma et al. (2004) demonstrated that the observed "new" ULSW was formed during years when LSW ventilation had ceased. Since Pickart et al. (1996, 1997) found considerable ULSW formation in the southern Labrador Sea in 1991/92 when simultaneously LSW formation took place in the central Labrador Sea, we cannot identify any years when ULSW formation has ceased. Our estimate thus represents a mean annual formation rate for the period $t_{0}-t_{n}=1930-97$, assuming that the CFC-11 inventory observed in 1997 has been introduced during these years. The resulting mean annual formation rate estimated from the combined subpolar and subtropical/tropical inventory in 1997 yields 3.2-3.3 Sv. As was pointed out by Smethie and Fine (2001) and R02, years prior to the mid-1970s do not contribute much to the CFC-11 inventory since the atmospheric concentration increased exponentially during this time span. About $5.7 \%$ of the CFC-11 inventory was introduced in the ULSW layer between 1930 and 1970. Afterward, the atmospheric concentrations increased linearly until 1990 , making up $57.2 \%$ of the 
inventory. The remaining $37.2 \%$ have entered the ULSW layer since then. The formation rate of 3.2-3.3 $\mathrm{Sv}$ is thus representative for the period 1970-97.

As Lazier et al. (2002) already pointed out, the formation of classical LSW ceased after 1997. The lack of supply of low-salinity/CFC-rich surface waters led to an annual increase in LSW salinities and a decrease in CFCs because of isopycnal mixing. With the classical LSW formation rate estimates given by R02 (4.4-5.6 $\mathrm{Sv})$ the mean combined ULSW/LSW formation rate calculated for 1930-97 but representative for the period 1970-97 is about 7.6-8.9 Sv.

\section{c. Formation rate variability 1998-2001}

The formation rates, referring to the subsequent four years (1998-2001), are assessed using Eq. (5). The inventory differences and corresponding formation rates are summarized in Table 4.

Depending on the applied method to handle data gaps, the resulting ULSW formation rate for 1998-99 gives 6.9-9.2 Sv. During this time the lack of LSW formation was almost compensated by an increase in the ULSW formation. In the subsequent two years, the ULSW formation weakened to 3.3-4.7. Because of the cessation of LSW ventilation, this estimate is identical to the combined ULSW/LSW formation rate for these years. If we further assume \pm 0.6 million moles as the smallest directly estimated uncertainty in the inventory, a conversion into a formation rate uncertainty results in $\pm 2 \mathrm{~Sv}$. As was stated, the formation rate is further dependent on the CFC-11 saturation. For saturations of $70 \%-100 \%$ the uncertainty of the formation rate is below $2 \mathrm{~Sv}$, regardless of using method 2 or 3 to handle data gaps. Thus, the decrease in the ULSW formation rates from 1998-99 to 2000-01 is significant.

The ULSW formation rate estimation has been repeated based on the corresponding CFC-12 inventories of 1999 and 2001 (4.2 million moles CFC-12 in 1999 and 4.9 million moles in 2001 as a result of method 3 to adjust coarse data resolution). The formation rates based on CFC-12 yielded 3.2-3.8 Sv in 2000-2001. Though smaller than the estimates derived from CFC11 inventories, they are still in a similar range.

\section{Potential regions for ULSW ventilation}

The Labrador Sea is the only region known for ULSW ventilation to occur (Pickart 1992; Pickart et al. 1996; Stramma et al. 2004). Here, we have verified to a first order whether additional ventilation regions for ULSW might exist. This is done by analyzing the climatological mixed layer depth (Monterey and Levitus
TABLE 4. CFC-11 inventory differences and corresponding ULSW formation rates $R_{2}$ for different periods and methods assuming $85 \%$ saturation.

\begin{tabular}{lcccccc}
\hline \hline & \multicolumn{2}{c}{$\begin{array}{c}\text { Inventory } \\
\text { difference } \\
\left(10^{6} \text { moles }\right)\end{array}$} & & \multicolumn{2}{c}{$\begin{array}{c}\text { Formation } \\
\text { rate } R_{2}(\mathrm{~Sv})\end{array}$} \\
\cline { 2 - 4 } \cline { 6 - 7 } Years & Added $\%$ & Extrap & $\begin{array}{c}\text { Formation } \\
\text { period }\end{array}$ & Added \% & Extrap \\
\hline $1997-99$ & 2.8 & 2.1 & $1998 / 99$ & 9.2 & 6.9 \\
$2001-1999$ & 1.0 & 1.4 & $2000 / 01$ & 3.3 & 4.7 \\
\hline
\end{tabular}

1997) for the month of March in conjunction with the corresponding surface density derived from the World Ocean Atlas 1994 (WOA 1994) (Levitus 1994). Because of harsh weather conditions the northern SPNA is in general not very well covered by wintertime hydrographic data. In the Labrador and Irminger Seas, the most recent open-ocean observations for March included in both climatologies are from the early 1980s. The winter climatologies thus represent oceanic conditions almost two decades prior to our observation period. The resulting climatological density field indicates that the outcropping of the isopycnal $\sigma_{\Theta}=27.68 \mathrm{~kg}$ $\mathrm{m}^{-3}$ during winter only occurs in the Labrador and Irminger Seas (Fig. 8). A third outcropping region exists to the northeast of Iceland. Deep mixed layer regions (700-900 m) are also found over the Rockall Bank and Rockall Trough. Yet, March isopycnals at $900 \mathrm{~m}$ do not exceed $\sigma_{\Theta}=27.64 \mathrm{~kg} \mathrm{~m}^{-3}$ in these regions. The density classes of ULSW are therefore supposed to be ventilated entirely in the western subpolar North Atlantic. In the data presented here, we did not find any evidence for ventilation in the eastern subpolar Atlantic, that is, to the east of the MAR.

Lavender et al. $(2000,2002)$ have provided estimates of mixed layer depth that point to convection reaching down to $800 \mathrm{~m}$ north of $60^{\circ} \mathrm{N}$ and $>800 \mathrm{~m}$ in the western Labrador Sea during winter 1996/97. This is to some extent reflected in the buoyancy content displayed in Fig. 9. The depth of penetration during convection depends on the stratification of the water column and the strength of the time-integrated winterly surface buoyancy fluxes. The integrated buoyancy content (BC) of a water column can be thought of as a measure for the stratification of the water column. It is given by

$$
\mathrm{BC}=\int_{-h}^{0}-g \frac{\rho-\rho_{0}}{\rho_{0}} d z,
$$

where $g\left(\mathrm{~m} \mathrm{~s}^{-2}\right)$ is the acceleration of gravity and $\rho$ and $\rho_{0}$ (both given in kilograms per meter cubed) are the actual and reference density. The buoyancy content is 

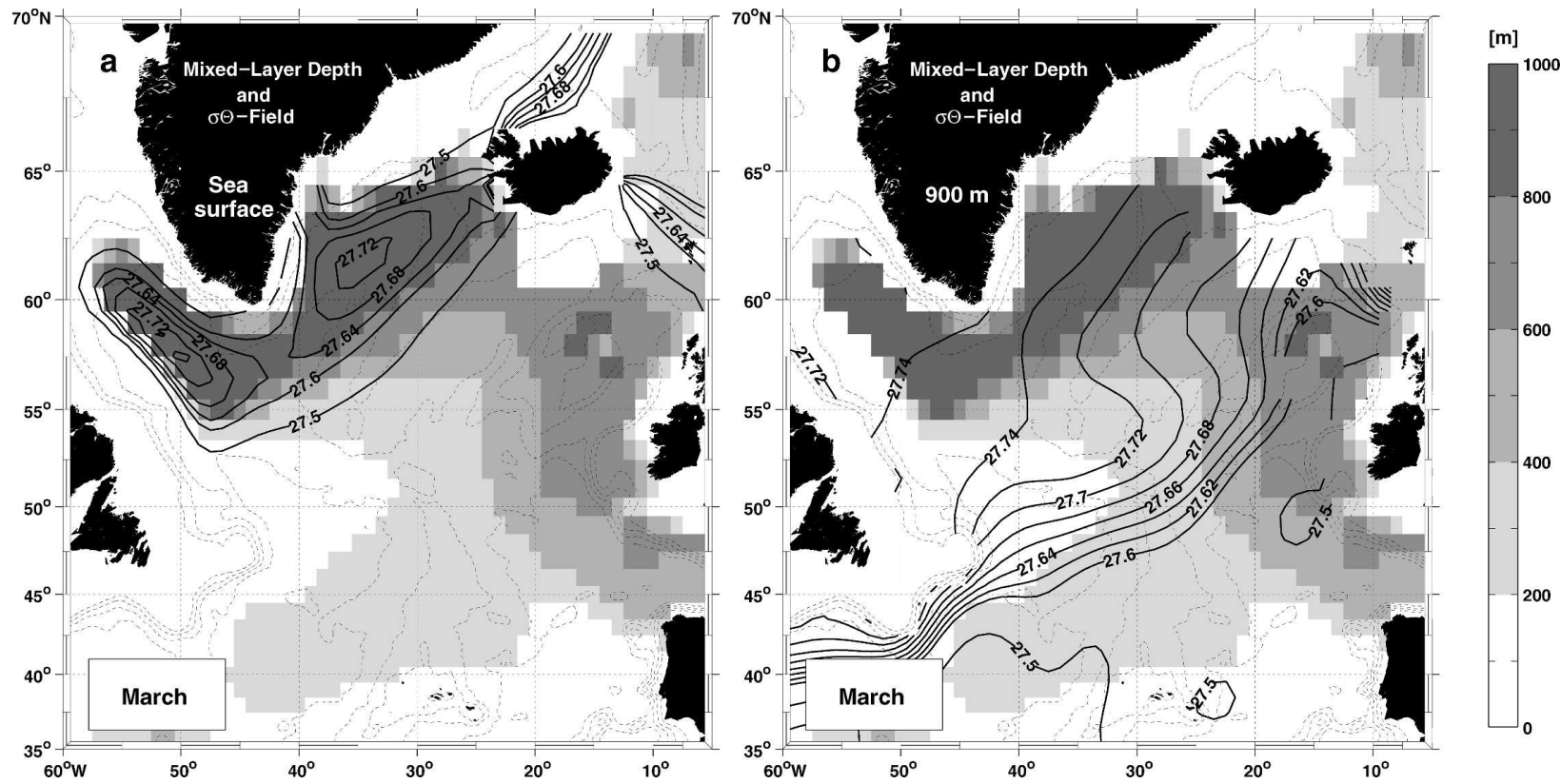

FIG. 8. Mixed layer depth (m) for climatological March, derived from Monterey and Levitus (1997) (gray shading). Superimposed are contours of the climatological potential density $\sigma_{\Theta}\left(\mathrm{kg} \mathrm{m}^{-3}\right)$ of March. Density field at (left) sea surface and (right) $900 \mathrm{~m}$. Densities are derived from WOA 1994 (Levitus 1994), only values $\geq 27.5 \mathrm{~kg} \mathrm{~m}^{-3}$ are shown. Bathymetric contours are given every $1000 \mathrm{~m}$.

derived from hydrographic profiles and calculated from the surface down to $-h$, the depth of the $\sigma_{\Theta}=27.68 \mathrm{~kg}$ $\mathrm{m}^{-3}$ isopycnal. It is proportional to the integral of density anomaly (relative to the reference density of the corresponding profile) contained above this depth. Higher values of the $\mathrm{BC}$ need a greater rate of buoyancy to be removed during winter for convection to reach the depth $-h$.
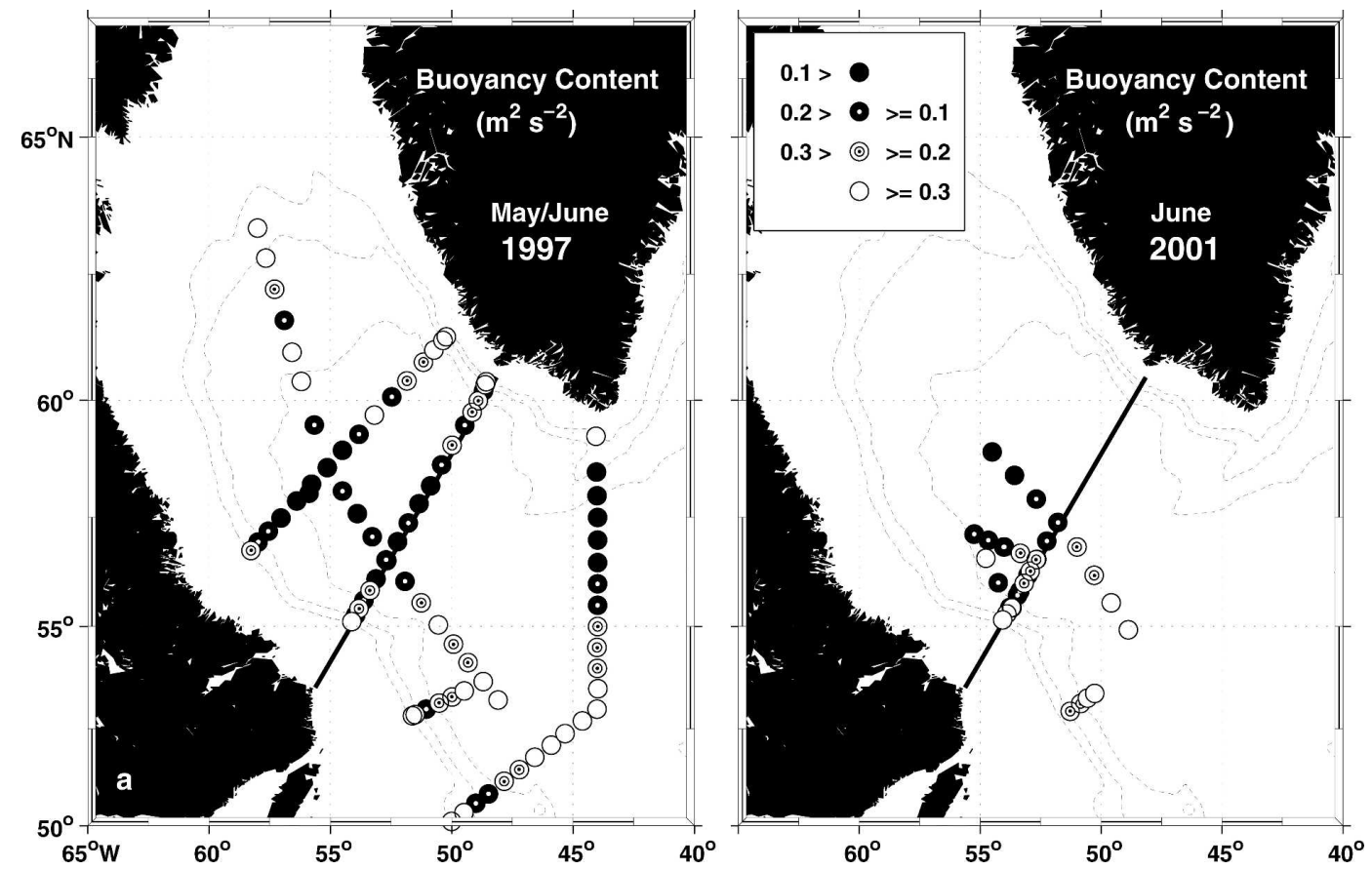

FIG. 9. Buoyancy content $\left(\mathrm{m}^{2} \mathrm{~s}^{-2}\right)$ of surface layers $\left[0 \mathrm{~m}-z\left(\sigma_{\Theta}=27.68 \mathrm{~kg} \mathrm{~m}^{-3}\right)\right]$, derived from CTD profiles, (left) May/June 1997 and (right) June 2001. Solid lines indicate the location of WOCE line AR7W. 


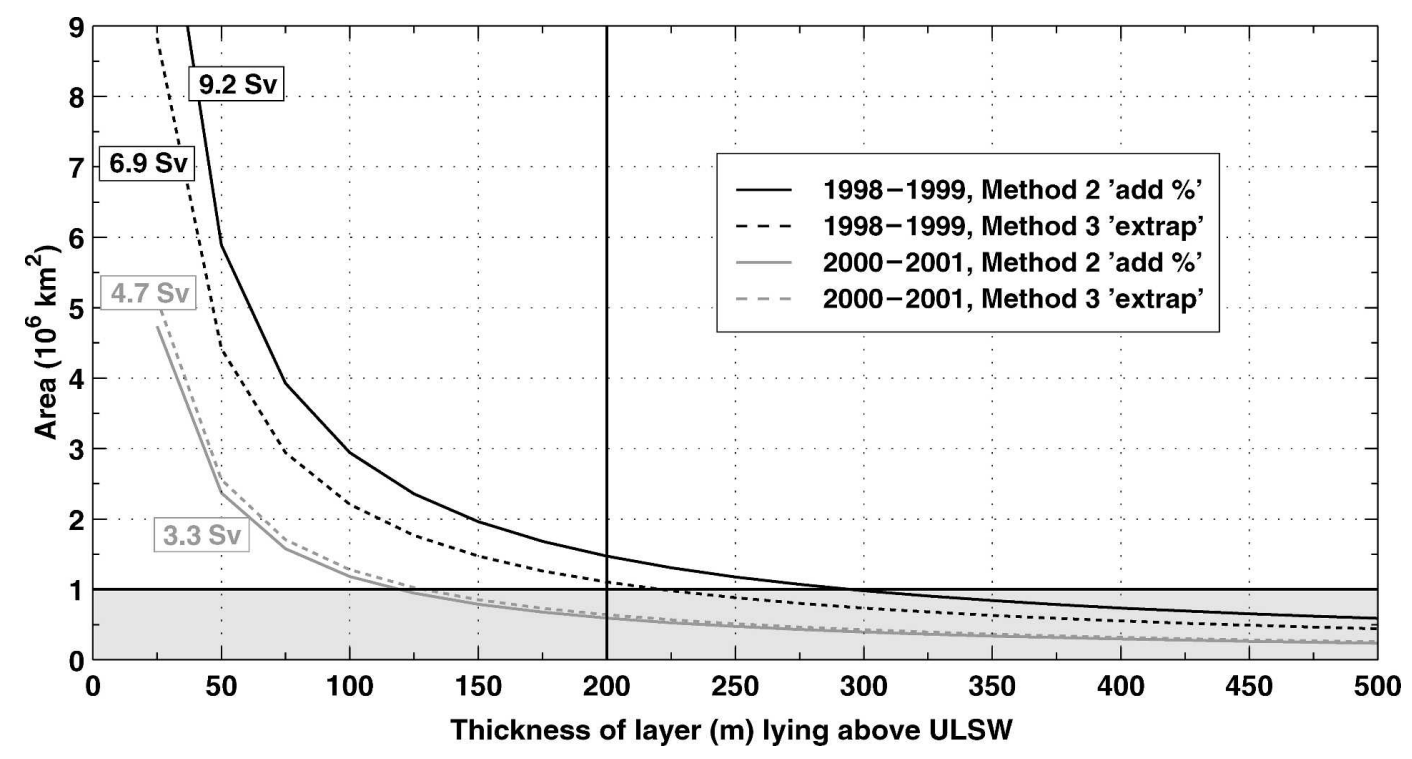

FIG. 10. Size of convection area derived from the calculated ULSW formation rates. Area estimates depend on the thickness of the water layer located on top of ULSW. The size of the Labrador Sea west of $45^{\circ} \mathrm{W}$, north of $50^{\circ} \mathrm{N}$, and with water depths greater than $500 \mathrm{~m}$ is about $1 \times 10^{6} \mathrm{~km}^{2}$, indicated by the gray shading.

Analyses of CTD profiles from June 1997 indicate BC minima in the central Labrador Sea, its western and northern boundary current region as well as south of Greenland at the exit of the Irminger Sea. Hydrographic profiles from June 2001, unfortunately, do not extend as far to the north as during summer 1997. However, data sampled along the axis of the Labrador Sea during summer 2001 (Stramma et al. 2004, their Fig. 4) indicate the highest CFC-11 concentrations and thickest ULSW layer in the northern part of this section. The location corresponds to the location of minimum BC estimates during 2001 (Fig. 9b).

Another region that might be considered for ULSW renewal is the Irminger Sea. The question, whether deep convection happens there, is open to discussion. As was found in historical data sampled during winter 1957/58 (Dietrich 1969) and in the WOA 1994 climatology, wintertime outcropping of the $\sigma_{\Theta}=27.68 \mathrm{~kg} \mathrm{~m}^{-3}$ isopycnal is likely in the Irminger Sea. Lavender et al. (2002) showed that local mixed layer depths of 600-800 m were reached in winter 1996/97 southwest of Greenland (west of about $45^{\circ} \mathrm{W}$ ). From the analyses of potential vorticity distributions and atmospheric conditions, Pickart et al. (2003b) argued that the most likely location for convection to occur is the southwestern Irminger Sea. The succeeding work of Pickart et al. (2003a) suggested the small-scale atmospheric Greenland tip jet to be the cause for Irminger Sea convection. Bacon et al. (2003) presented results from ship measurements and profiling floats from this region that indicate local formation of convective plumes in the southeast of Greenland during winter 1996/97. Surface densities at that time exceeded $\sigma_{\Theta}=27.68 \mathrm{~kg} \mathrm{~m}^{-3}$. Concerning the observation period 1997-2001 the formation rates previously estimated provide some valuable hints. With $1 \mathrm{~Sv}$ corresponding to a volume of 3.2 $\times 10^{13} \mathrm{~m}^{3}$ formed in one year, the formation rates of ULSW can be used to estimate the size of the convection area. The area of the Labrador Sea north of $50^{\circ} \mathrm{N}$, west of $45^{\circ} \mathrm{W}$, and for water depths $>500 \mathrm{~m}$ is about $1 \times 10^{6} \mathrm{~km}^{2}$. However, this large area is probably not completely affected by wintertime convection. For example, Lilly et al. (1999) and R02 estimated the size of the LSW ventilation region to be $0.3 \times 10^{6} \mathrm{~km}^{2}$. The ULSW formation rates of 6.9-9.2 Sv during 1998/99 and 3.3-4.7 Sv in 2000/01 correspond to an area of (1.1-1.5) $\times 10^{6} \mathrm{~km}^{2}$ and $(0.5-0.8) \times 10^{6} \mathrm{~km}^{2}$, respectively, if water prior to convection occupies the upper $200 \mathrm{~m}$ of the water column. During the summers of the investigated period, $200 \mathrm{~m}$ is the typical depth of the $\sigma_{\Theta}=$ $27.68 \mathrm{~kg} \mathrm{~m}^{-3}$ (Stramma et al. 2004). It is this water lying on top of ULSW that must be transformed to ULSW during wintertime. With this assumption, at least in 1998/99 the estimated probable convection area does not fit entirely into the Labrador Sea. Figure 10 shows the dependence of the estimated convection area on the layer thickness of water lying on top of ULSW. The greater estimate of ULSW formation during 1998/99 $(9.2 \mathrm{~Sv})$ indicates that this conclusion also holds, if the layer above ULSW is up to $300 \mathrm{~m}$ thick. If a layer thickness of $400 \mathrm{~m}$ is assumed, the estimated ULSW convection region is still more than 2 times that esti- 
mated by Lilly et al. (1999) and R02 for LSW. These results might serve as an indication that the Labrador Sea probably was not the only location favoring ULSW formation during these years.

We further investigated temperature profiles received from one of the very few profiling floats that drifted in the Irminger Sea during late winter 1997/98 (data available from the Argo project Web site). At least four profiles indicated a homogenous temperature distribution in the upper 300-400 $\mathrm{m}$ (Fig. 11). The float, however, has not been equipped with a conductivity sensor, so there are no density profiles available for this time. In the subsequent summer, CTD profiles were taken within the framework of VEINS close to the wintertime positions of the Argo float. The upper limit of ULSW $\left(\sigma_{\Theta}=27.68 \mathrm{~kg} \mathrm{~m}^{-3}\right)$ was located at $300 \mathrm{dbar}$ at the offshore end of this section, in contrast to $850 \mathrm{dbar}$ on the Greenland side. Local convection reaching down to $300-400 \mathrm{~m}$ might therefore be sufficient to affect the ULSW layer. Furthermore, the offshore end of this section was associated with the lowest salinities within the ULSW as well as the LSW layer. The gradients of layer thickness and CFC-11, previously presented, suggest that the ULSW formation in the Labrador Sea is of greater importance for the accumulation of CFC-11 in the southwestern Irminger Sea than local convection. From the analyses presented by Stramma et al. (2004) and our own results, the main location of ULSW formation in recent years was not the southern Labrador Sea, as Pickart et al. $(1996,1997)$ found to be the case during the early 1990s.

\section{ULSW formation variability on decadal scales}

We do not have enough historical CFC data to infer longer time series of ULSW formation rates. However, the availability of more than 50 years of historical hydrographic data in the Labrador Sea allows us to look at the variability of hydrographic properties on interdecadal times scales and thus to deduce information about the formation history. For both ULSW and the denser classical LSW, time series of layer thickness have been reconstructed from various databases with respect to the period 1948-2003 (cf. Fig. 12). Data are from the Bedford Institute of Oceanography, HydroBase (Curry 1996), National Oceanographic Data Center (1991), WHPO, and SFB 460. The chosen profiles are located at or in the vicinity of the former Ocean Weather Station (OWS) Bravo $\left(56^{\circ} 30^{\prime} \mathrm{N}, 51^{\circ} \mathrm{W}\right.$; cf. Fig. 12 , right), which is close to the site of deep convection to occur. The considered profiles have sample levels reaching deeper than $2500 \mathrm{~m}$. The bottle profiles were interpolated on a regular pressure grid (grid spacing 20 dbar) to increase resolution, while the corresponding CTD data were subsampled at 20 dbar to assure monotonicity of the density with depth. Water masses rather mix along isopycnals than along isobars. Therefore, in a second step, all profiles were interpolated on $\sigma_{\Theta}$ surfaces (grid spacing $0.001 \mathrm{~kg} \mathrm{~m}^{-3}$ ). Profiles from particular cruises and/or specific periods were averaged along isopycnal surfaces to generate mean profiles. They served to calculate layer properties.

Despite the OWS Bravo sampling program, data available for the central Labrador Sea have been sampled irregularly in time. The majority of profiles are from early to late summer (May-September), which is certainly due to the harsh weather conditions during other seasons. The dataset is not extensive enough to resolve seasonality for the considered years, 1948-2003. It is thus not possible to remove the seasonal cycle. Since the ULSW layer is located close to the surface, only profiles from the months June-August are investigated in the following analyses. Profiles from earlier or later months are only considered when summer profiles are not available and otherwise greater time gaps would arise. The greatest temporal data gaps are present in the period 1975-83.

According to Curry et al. (1998), changes in the LSW layer thickness and in the intensity of wintertime convection are directly related. While strong convection results in a thick layer, the effect of weak/shallow convection is a thin LSW layer. The shape of the reconstructed LSW time series in Fig. 12 strongly resembles the one provided by Curry et al. (1998), though these authors have chosen a somewhat broader definition for LSW, resulting in larger thickness estimates in their study. The obvious strong increase in LSW layer thickness in 1972 and 1988 is related to the onset of deep convection. During the preceding years, the Labrador Sea was occupied by the so-called Great Salinity Anomalies (Dickson et al. 1988; Belkin et al. 1998) that advected excess freshwater. These anomalies have been attributed to be one likely cause for the cessation of deep convection at that time.

The time series of ULSW and LSW layer thickness (Fig. 12) are strongly anticorrelated with a correlation coefficient of -0.85 . The deep convection of the early 1970s and 1990s eroded the existing ULSW layer, while in the subsequent postconvection phases, the onset of restratification increased the ULSW layer thickness.

Throughout the decades, the formation of ULSW in the Labrador Sea seems to be a common feature, which may account for the permanent ULSW signal present in the subtropical to tropical North Atlantic (e.g., Weiss et al. 1985; Fine and Molinari 1988; Smethie 1993; Rhein et al. 1998). 

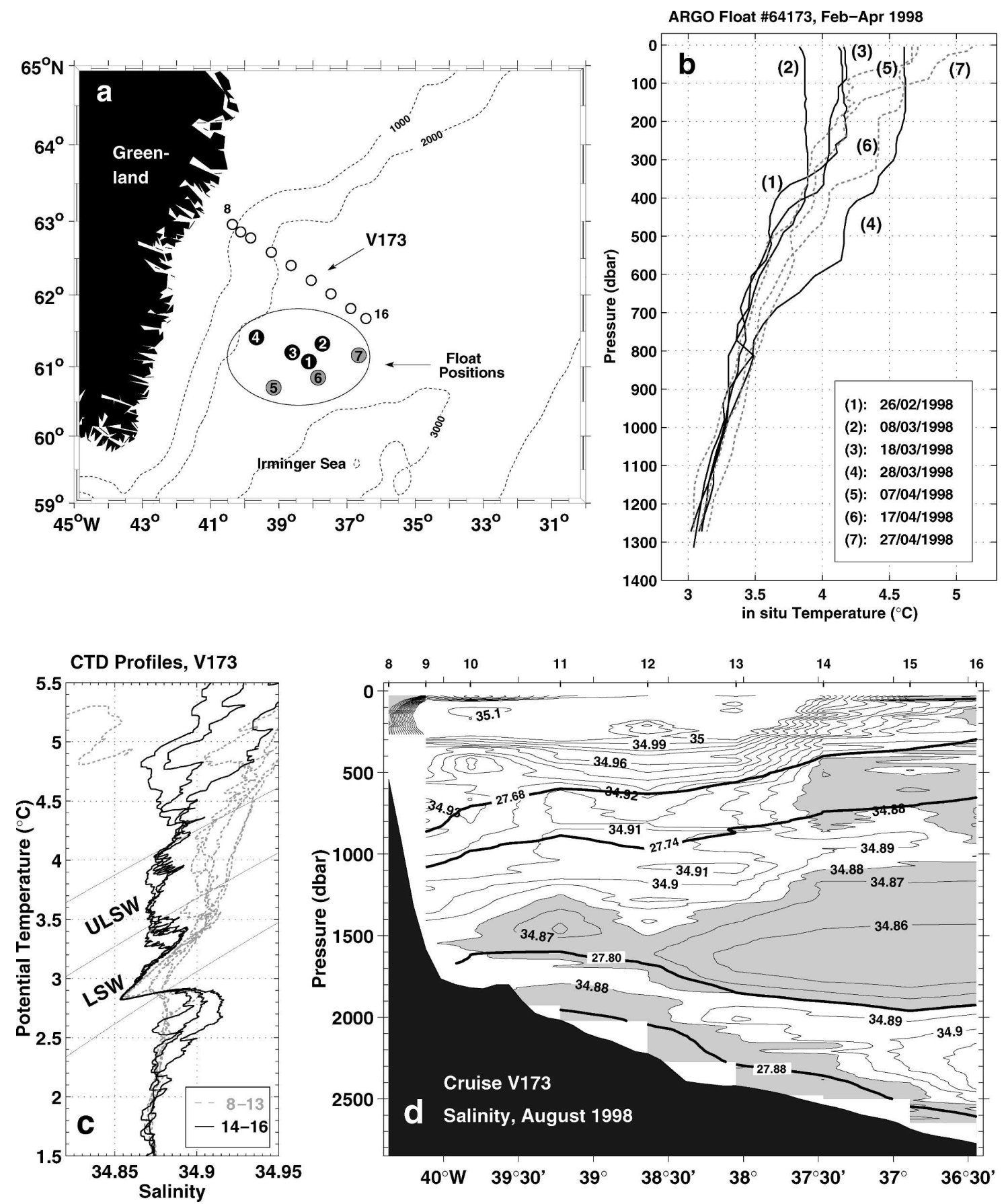

FIG. 11. (a) Location of temperature profiles from Argo float No. 64173 taken during winter 1997/98 in the Irminger Sea (numbered circles within ellipse). The positions of CTD profiles from a subsequent summer cruise (R/V Valdivia, V173, August 1998) are marked by white circles. (b) Corresponding temperature profiles derived from the Argo float. (c) The $T-S$ diagram from CTD profiles of cruise V173. (d) Salinity section of cruise V173. Salinities below 34.88 psu are shaded gray. Data are courtesy of IFM Hamburg.

\section{Summary and conclusions}

In the present study we examined the large-scale spreading, CFC-11 inventories, and formation rates of
ULSW, a water mass that is convectively formed in the Labrador Sea during winter (Pickart et al. 1996, 1997) and is increasingly ventilated during recent years (Stramma et al. 2004). We presented horizontal param- 

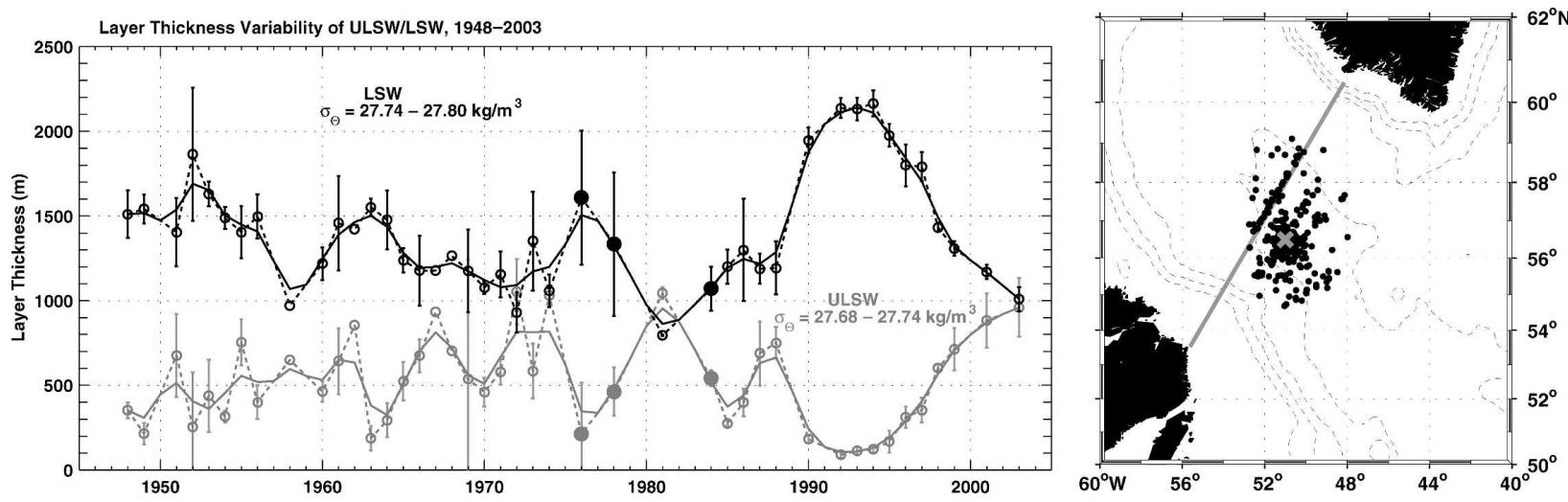

FIG. 12. (left) Time series of layer thickness (m) for classical (black curve) and ULSW (gray curve), given for the period 1948-2003. Open circles indicate the individual mean estimate derived from summer data with vertical bars as the corresponding standard deviation. Filled circles denote estimates solely based on winter data. A 3-yr filter is applied to smooth the time series (solid lines). (right) Location of included Labrador Sea profiles (black dots). The gray line marks the course of WOCE line AR7W; the gray cross is the position of OWS Bravo.

eter maps derived from observational hydrographic and tracer data of the years 1997, 1999, and 2001, which had been gridded using a topography-following inter/ extrapolation scheme similar to Davis (1998), Fischer and Schott (2002), and Rhein et al. (2002). We discussed the spreading pathways and highlighted the changes throughout the years. From the gridded fields, we estimated the CFC-11 inventories of ULSW for 1997, 1999, and 2001 and the corresponding formation rates.

The large-scale distributions of watermass properties indicate a spreading of ULSW that is similar to that of LSW. ULSW ventilated during the late 1990s is not confined to the western boundary current. It rather spreads throughout the subpolar North Atlantic on similar pathways as LSW and also enters the Eastern Basin. This is consistent with results by Lavender et al. (2000, 2005).

The dominant change leading to increased CFC inventories in 1999 and 2001 was a considerable thickening of the ULSW layer especially in the Labrador Sea. This was associated with a spreading of high CFC-11 concentrations from the northern and central Labrador Sea into the Newfoundland Basin and the Irminger Sea. The greater change occurred from 1997 to 1999 rather than from 1999 to 2001.

The total ULSW CFC-11 inventory of 1997 in the subpolar North Atlantic is $6.0 \pm 0.6$ million moles. Together with the estimate for the subtropical and tropical Atlantic of 5.0 million moles (D. A. LeBel et al. 2002, unpublished manuscript), the total inventory of the Atlantic Ocean exceeded 11.0 million moles in 1997. In 1999 , the ULSW inventory in the subpolar North Atlantic was $8.1 \pm 0.6$ million moles, and in $20019.5 \pm 0.6$ million moles. The inventory increase was more pro- nounced between 1997 and 1999 than between 1999 and 2001.

The mean annual formation rate for ULSW in the period 1970-97 is 3.2-3.3 Sv. This estimate was derived from the total Atlantic Ocean inventory. The formation rate for the years 1998-99 was considerably greater and gave 6.9-9.2 Sv. In 2000-01, it weakened to 3.3-4.7 Sv. Prior to 1998, the combined mean formation rates of ULSW (3.2-3.3 Sv) and LSW [4.4-5.6 Sv, estimated by Rhein et al. (2002)] were about 7.6-8.9 Sv. In 1998-99, the high ULSW formation was almost compensated for by the lack of classical LSW formation. The associated uncertainty in the formation rates was estimated using different methods. Estimates gave an error of about $\pm 2 \mathrm{~Sv}$.

We have presented indications that in 1998-99 ULSW probably could not be formed solely in the Labrador Sea. The most likely region for additional formation of ULSW seems to be the Irminger Sea. Nevertheless, the northern and central Labrador Sea are the most important sites for ULSW formation at that time.

Reconstructed hydrographic time series referring to layer thickness of LSW and ULSW in the period 19482003 show large decadal variability in both layers that are related to changes in the wintertime convection. Both time series are strongly anticorrelated (correlation coefficient -0.85 ).

Whether the considerable decrease of the combined ULSW/LSW formation rate at the beginning of the twenty-first century will have an impact on the deepwater export into the subtropical Atlantic remains an intriguing question for future works.

Acknowledgments. We thank captains, crews, and chief scientists of the various cruises and M. Schütt, K. 
Bulsiewicz, O. Plähn, and R. Steinfeldt for analyzing and processing the German CFC data set. Most of the hydrographic data presented in the analyses of layer thicknesses are from SFB 460 and the WHPO. We very much thank the particular cruise PIs and especially the CFC PIs P. Jones (BIO), R. Weiss (SIO), W. Roether (IUP), T. Tanhua (UGot, now at IFM-GEOMAR), and D. Smythe-Wright (NOCS) for making their data public. We acknowledge the CTD data contributions from Labrador Sea Deep Convection Experiment Group (Krahmann et al. 2003). We also thank J. Meincke, IFM Hamburg, Germany, for the use of their unpublished CTD data from the Irminger Sea; John Lazier (BIO) for a set of historical profiles from the Labrador Sea; and Ruth Curry (WHOI) for making HydroBase available to the public. Two anonymous reviewers made very valuable comments and suggestions on the original manuscript, which helped to clarify our statements. Funding was granted by the Deutsche Forschungsgemeinschaft as part of the SFB 460 "Dynamics of Thermohaline Circulation Variability." Support for W. Smethie and D. LeBel was provided by U.S. NSF Grant Oce 01-18127.

\section{REFERENCES}

Azetsu-Scott, K., E. P. Jones, I. Yashayaev, and R. M. Gershey, 2003: Time series study of CFC concentrations in the Labrador Sea during deep and shallow convection regimes (19912000). J. Geophys. Res., 108, 3354, doi:10.1029/2002JC001317.

Bacon, S., W. J. Gould, and Y. Jia, 2003: Open-ocean convection in the Irminger Sea. Geophys. Res. Lett., 30, 1246, doi:10.1029/2002GL016271.

Belkin, I. M., S. Levitus, J. Antonov, and S. A. Malmberg, 1998: "Great Salinity Anomalies" in the North Atlantic. Progress in Oceanography, Vol. 41, Pergamon, 1-68.

Böning, C. W., M. Rhein, J. Dengg, and C. Dorow, 2003: Modeling CFC inventories and formation rates of Labrador Sea Water. Geophys. Res. Lett., 30, 1050, doi:10.1029/ 2002 GL014855.

Bower, A. S., and Coauthors, 2002: Directly measured mid-depth circulation in the northeastern North Atlantic Ocean. Nature, 419, 603-607.

Clarke, R. A., and J.-C. Gascard, 1983: The formation of Labrador Sea Water. Part I: Large-scale processes. J. Phys. Oceanogr., 13, 1764-1778.

Cunnold, D. M., P. M. Fraser, R. F. Weiss, R. G. Prinn, P. G. Simmonds, S. R. Miller, F. N. Alyea, and A. J. Crawford, 1994: Global trends and annual releases of $\mathrm{CCl}_{3} \mathrm{~F}$ and $\mathrm{CCl}_{2} \mathrm{~F}_{2}$ estimated from ALE/GAGE and other measurements from July 1987 to June 1991. J. Geophys. Res., 99 (D1), 1107-1126.

Curry, R., 1996: A database of hydrographic stations and tools for climatological analysis. Woods Hole Oceanographic Institution Tech. Rep. WHOI-96-01, 50 pp.

_ M. S. McCartney, and T. M. Joyce, 1998: Oceanic transport of subpolar climate signals to mid-depth subtropical waters. Nature, 391, 575-577.

Davis, R. E., 1998: Preliminary results from directly measuring middepth circulation in the tropical and South Pacific. J. Geophys. Res., 103 (C11), 24 619-24 639.

Dickson, R. R., J. Meincke, S.-A. Malmberg, and A. J. Lee, 1988: The "Great Salinity Anomaly" in the northern North Atlantic 1968-1982. Progress in Oceanography, Vol. 20, Pergamon, 103-151.

Dietrich, G., 1969: Atlas of the Hydrography of the Northern North Atlantic Based on the Polar Front Survey of the International Geophysical Year, Winter and Summer 1958. Conseil International pour l'Exploration de la Mer, Service Hydrographique, Charlottenlund Slot, Denmark, 140 pp.

Fine, R. A., and R. L. Molinari, 1988: A continuous deep western boundary current between Abaco $\left(26.5^{\circ} \mathrm{N}\right)$ and Barbados $\left(13^{\circ} \mathrm{N}\right)$. Deep-Sea Res., 35, 1441-1450.

Fischer, J., and F. A. Schott, 2002: Labrador Sea Water tracked by profiling floats-From the boundary current into the open North Atlantic. J. Phys. Oceanogr., 32, 573-584.

Girton, J. B., T. B. Sanford, and R. H. Käse, 2001: Synoptic sections of the Denmark Strait Overflow. Geophys. Res. Lett., 28, 1619-1622.

Häkkinen, S., 2002: Freshening of the Labrador Sea surface waters in the 1990s: Another Great Salinity Anomaly? Geophys. Res. Lett., 24, 2232, doi:10.1029/2002GL015243.

Hurrell, J. W., 1995: Decadal trends in the North Atlantic Oscillation: Regional temperatures and precipitation. Science, 269, 676-679.

Jenkins, W. J., and P. B. Rhines, 1980: Tritium in the deep North Atlantic Oceans. Nature, 286, 877-880.

Kalnay, E., and Coauthors, 1996: The NCEP/NCAR 40-Year Reanalysis Project. Bull. Amer. Meteor. Soc., 77, 437-471.

Koltermann, K. P., A. V. Sokov, V. P. Tereschenkov, S. A. Dobroliubov, K. Lorbacher, and A. Sy, 1999: Decadal changes in the thermohaline circulation of the North Atlantic. Deep-Sea Res., 46B, 109-138.

Krahmann, G., and Coauthors, 2003: The Labrador Sea Deep Convection Experiment data collection. Geochem., Geophys., Geosyst., (G3), 4, 1091, doi:10.1029/2003GC000536.

Krauss, W., 1995: Currents and mixing in the Irminger Sea and in the Iceland Basin. J. Geophys. Res., 100 (C6), 10 851-10 871.

Lab Sea Group, 1998: The Labrador Sea Deep Convection Experiment. Bull. Amer. Meteor. Soc., 79, 2033-2058.

Lavender, K. L., R. E. Davis, and W. B. Owens, 2000: Mid-depth recirculation observed in the interior Labrador and Irminger seas by direct velocity measurements. Nature, 407, 66-69.

,-- , and,- 2002 : Observations of open-ocean deep convection in the Labrador Sea from subsurface floats. J. Phys. Oceanogr., 32, 511-526.

_ W. B. Owens, and R. E. Davis, 2005: The mid-depth circulation of the subpolar North Atlantic Ocean as observed by subsurface floats. Deep-Sea Res., 52A, 767-785.

Lazier, J. R. N., 1973: The renewal of Labrador Sea Water. DeepSea Res., 20, 341-353.

_ 1980: Oceanographic conditions at Ocean Weather Ship Bravo, 1964-1974. Atmos.-Ocean, 18, 227-238.

_, R. Hendry, A. Clarke, I. Yashayaev, and P. B. Rhines, 2002: Convection and restratification in the Labrador Sea, 19902000. Deep-Sea Res., 49A, 1819-1835.

Levitus, S., 1994: World Ocean Atlas 1994. CD-ROM Data Sets, National Oceanographic Data Center, NOAA.

Lilly, J. M., P. B. Rhines, M. Visbeck, R. Davis, J. R. N. Lazier, F. Schott, and D. Farmer, 1999: Observing deep convection in the Labrador Sea during winter 1994/95. J. Phys. Oceanogr., 29, 2065-2098. 
Marshall, J., and F. Schott, 1999: Open-ocean convection: Observations, theory, and models. Rev. Geophys., 37 (1), 1-64.

Monterey, G., and S. Levitus, 1997: Seasonal Variability of Mixed Layer Depth for the World Ocean. NOAA Atlas NESDIS 14, U.S. Government Printing Office, 96 pp.

National Oceanographic Data Center, 1991: Global Ocean Temperature and Salinity Profiles. Vol. 1, CD-ROM, NOAA/ NESDIS.

Orsi, A. H., G. C. Johnson, and J. L. Bullister, 1999: Circulation, mixing and production of Antarctic Bottom Water. Progress in Oceanography, Vol. 43, Pergamon, 55-110.

Pickart, R. S., 1992: Water mass components of the North Atlantic deep western boundary current. Deep-Sea Res., 39, 15531572.

— W. M. Smethie, J. R. N. Lazier, E. P. Jones, and W. J. Jenkins, 1996: Eddies of newly formed Upper Labrador Sea Water. J. Geophys. Res., 101 (C9), 20 711-20 726.

— , M. A. Spall, and J. R. N. Lazier, 1997: Mid-depth ventilation in the western boundary current system of the subpolar gyre. Deep-Sea Res., 44, 1025-1054.

,-- M. H. Ribergaard, G. W. K. Moore, and R. F. Milliff, 2003a: Deep convection in the Irminger Sea forced by the Greenland tip jet. Nature, 424, 152-156.

_- F. Straneo, and G. W. K. Moore, 2003b: Is Labrador Sea Water formed in the Irminger Basin? Deep-Sea Res., 50A, 23-52.

Rhein, M., O. Plähn, R. Bayer, L. Stramma, and M. Arnold, 1998: The temporal evolution of the tracer signal in the deep western boundary current, tropical Atlantic. J. Geophys. Res., 103 (C8), 15 869-15 883.

— inventory and formation rates. J. Phys. Oceanogr., 32, 648665.

Schott, F., L. Stramma, and J. Fischer, 1999a: Interaction of the North Atlantic Current with the deep Charlie Gibbs Fracture Zone throughflow. Geophys. Res. Lett., 26, 369-372.

, K.-P. Koltermann, L. Stramma, A. Sy, R. Zahn, and W. Zenk, 1999b: North Atlantic 1997, Cruise No. 39, 18 April-14 September 1997. METEOR-Berichte 99-1, Universität Hamburg, $197 \mathrm{pp}$.

, J. Meincke, G. Meinicke, S. Neuer, and W. Zenk, 2000: North Atlantic 1999, Cruise No. 45, 18 May-4 November 1999. METEOR-Berichte 00-4, Universität Hamburg, 161 pp.

, J. Fischer, J. Holfort, and W. Zenk, 2002: North Atlantic 2001, Cruise No. 50, 7 May-12 August 2001. METEORBerichte 02-2, Universität Hamburg, 123 pp.
Schott, F. A., R. Zantopp, L. Stramma, M. Dengler, J. Fischer, and M. Wibaux, 2004: Circulation and deep water export at the western exit of the subpolar North Atlantic. J. Phys. Oceanogr., 34, 817-843.

Smethie, W. M., 1993: Tracing the thermohaline circulation in the western North Atlantic using chlorofluorocarbons. Progress in Oceanography, Vol. 31, Pergamon, 51-99.

— , and R. A. Fine, 2001: Rates of North Atlantic Deep Water formation calculated from chlorofluorocarbon inventories. Deep-Sea Res., 48A, 189-215.

- — - A. Putzka, and E. P. Jones, 2000: Tracing the flow of North Atlantic Deep Water using chlorofluorocarbons. $J$. Geophys. Res., 105 (C6), 14 297-14 323.

Stramma, L., D. Kieke, M. Rhein, I. Yashayaev, F. Schott, and K.-P. Koltermann, 2004: Deep water changes at the western boundary of the subpolar North Atlantic during 1996 to 2001. Deep-Sea Res., 51A, 1033-1056.

Straneo, F., R. S. Pickart, and K. Lavender, 2003: Spreading of Labrador Sea Water: An advective-diffusive study based on Lagrangian data. Deep-Sea Res., 50A, 701-719.

Sy, A., M. Rhein, J. R. N. Lazier, K. P. Koltermann, J. Meincke, A. Putzka, and M. Bersch, 1997: Surprisingly rapid spreading of newly formed intermediate waters across the North Atlantic Ocean. Nature, 386, 675-679.

Talley, L. D., and M. S. McCartney, 1982: Distribution and circulation of Labrador Sea Water. J. Phys. Oceanogr., 12, 11891204.

Tichelaar, B. W. and L. J. Ruff, 1989: How good are our best models? Jackknifing, bootstrapping, and earthquake depth. Eos, Trans. Amer. Geophys. Union, 70, 605-606.

Walker, S. J., R. F. Weiss, and P. K. Salameh, 2000: Reconstructed histories of the annual atmospheric mole fractions for the halocarbons CFC-11, CFC-12, CFC-113 and carbon tetrachloride. J. Geophys. Res., 105 (C6), 14 285-14 296.

Wallace, D. W. R., and J. R. N. Lazier, 1988: Anthropogenic chlorofluoromethanes in newly formed Labrador Sea Water. Nature, 332, 61-63.

Warner, M. J., and R. F. Weiss, 1985: Solubilities of chlorofluorocarbons 11 and 12 in water and seawater. Deep-Sea Res., 32, 1485-1497.

Weiss, R. F., J. L. Bullister, R. H. Gammon, and M. J. Warner, 1985: Atmospheric chlorofluoromethanes in the deep equatorial Atlantic. Nature, 314, 608-610.

Willebrand, J., and Coauthors, 2001: Circulation characteristics in three eddy-permitting models of the North Atlantic. Progress in Oceanography, Vol. 48, Pergamon, 123-161. 